\title{
Spectroscopy: Developments in Instrumentation and Analysis
}

\author{
By Vincent Baeten and Pierre Dardenne \\ Quality Department of Agricultural Products. Agricultural Research Centre of Gembloux. \\ Chaussée de Namur, 24. 5030 Gembloux. Belgium. \\ Tel: 32/81/62 03 50, Fax: 32/81/62 03 88. E-mail: baeten@cragx.fgov.be
}

\section{CONTENTS}

1. Introduction

2. Why spectroscopic techniques

2.1. Analytical characteristics

2.2. Spectroscopic characteristics

2.3. Instrumental characteristics

3. Some theoretical elements

3.1. Classical theory

3.2. Quantum theory

3.3. Absorption and scattering: band position and intensity

4. Selecting the information

5. Spectroscopic instrumentation

5.1. Near-infrared instrument

5.1.1. Classical instrument

5.1.2. Microscope and camera

5.1.3. Sample presentation

5.2. Mid-infrared instrument

5.2.1. Microscope and camera

5.2.2. Sample presentation

5.3. Raman instrument

5.3.1. Microscope and camera

5.3.2. Sample presentation

6. Applications

6.1. Quantitative analysis

6.1.1. Determination of fat content

6.1.2. Determination of major and minor components in lipid

6.2. Qualitative analysis

References

\section{RESUMEN}

Espectroscopía: Desarrollo en instrumentación y análisis.

Este artículo de revisión presenta las características, ventajas, límites y potencial de tres técnicas espectroscópicas: las espectroscopias del infrarrojo cercano, del medio infrarrojo y Raman. Se presentan, y discuten brevemente, los aspectos teóricos relacionados con estas técnicas, la información que pueden suministrar, y las principales características de la instrumentación. La última parte de la revisión esta dedicada a las aplicaciones de la espectroscopia en análisis de alimentos, con especial énfasis en análisis de lípidos. Las ilustraciones y los ejemplos se han elegido para demostrar la importancia de las técnicas espectroscópicas en los procesos en-línea y en los laboratorios en el análisis de componentes mayoritarios y minoritarios.

PALABRAS-CLAVE: Análisis - Autentificación - Espectroscopia infrarrojo cercano- Espectroscopia infrarrojo medio - Espectroscopia Raman - Microscopio - Quimiometria.

\section{SUMMARY}

Spectroscopy: Developments in instrumentation and analysis.

This review presents the characteristics, advantages, limits and potential of three spectroscopic techniques: near-infrared spectroscopy (NIR), mid-infrared spectroscopy (MIR) and Raman spectroscopy. The theoretical aspects related with these techniques, the information that can supplied and the main features of the instrumentation are presented and briefly discussed. The last part of the review concerns the application of the spectroscopy to food analysis, with special emphasis on the lipid analysis. The illustrations and examples have been chosen to demonstrate the importance of spectroscopic techniques both in process (on-line) control and in laboratories for the analysis of major or minor compounds.

KEY-WORDS: Analysis - Authentication - Chemometrics - Midinfrared spectroscopy - Near-infrared spectroscopy - Raman spectroscopy.

\section{INTRODUCTION}

In recent years, spectroscopic techniques have come to be regarded as attractive and promising analytical tools for analyses conducted in research, control or industrial laboratories. These techniques are increasingly considered by analysts as an obvious solution. This trend stems from instrumental developments, the extensive use of computers and the development of appropriate chemometric procedures. Daily, new applications of spectroscopic techniques in the fields of chemistry, drugs, the agro-food sector, life sciences and environmental analysis are being demonstrated and published. The objective should be not only to extend the field of application of spectroscopic techniques, but also to use them as a matter of course in control and industrial laboratories and to develop (according to internationally accepted guidelines) fully validated spectroscopic methods.

This paper presents the characteristics, advantages, limitations and potential of three spectroscopic techniques: near-infrared spectroscopy (NIR), mid-infrared spectroscopy (MIR) and Raman spectroscopy. Special emphasis is placed on the application of these techniques to lipid analysis. The illustrations and examples have been chosen to demonstrate the importance of infrared (NIR and MIR) and Raman spectroscopies both in process (on-line) control and in laboratories for the analysis of major or minor compounds. There are many books and papers on the subject; most of the references included here have been selected for their relevance and clarity. 
Table I

Analytical, spectroscopic and instrumental characteristics of NIR, MIR and Raman spectroscopies

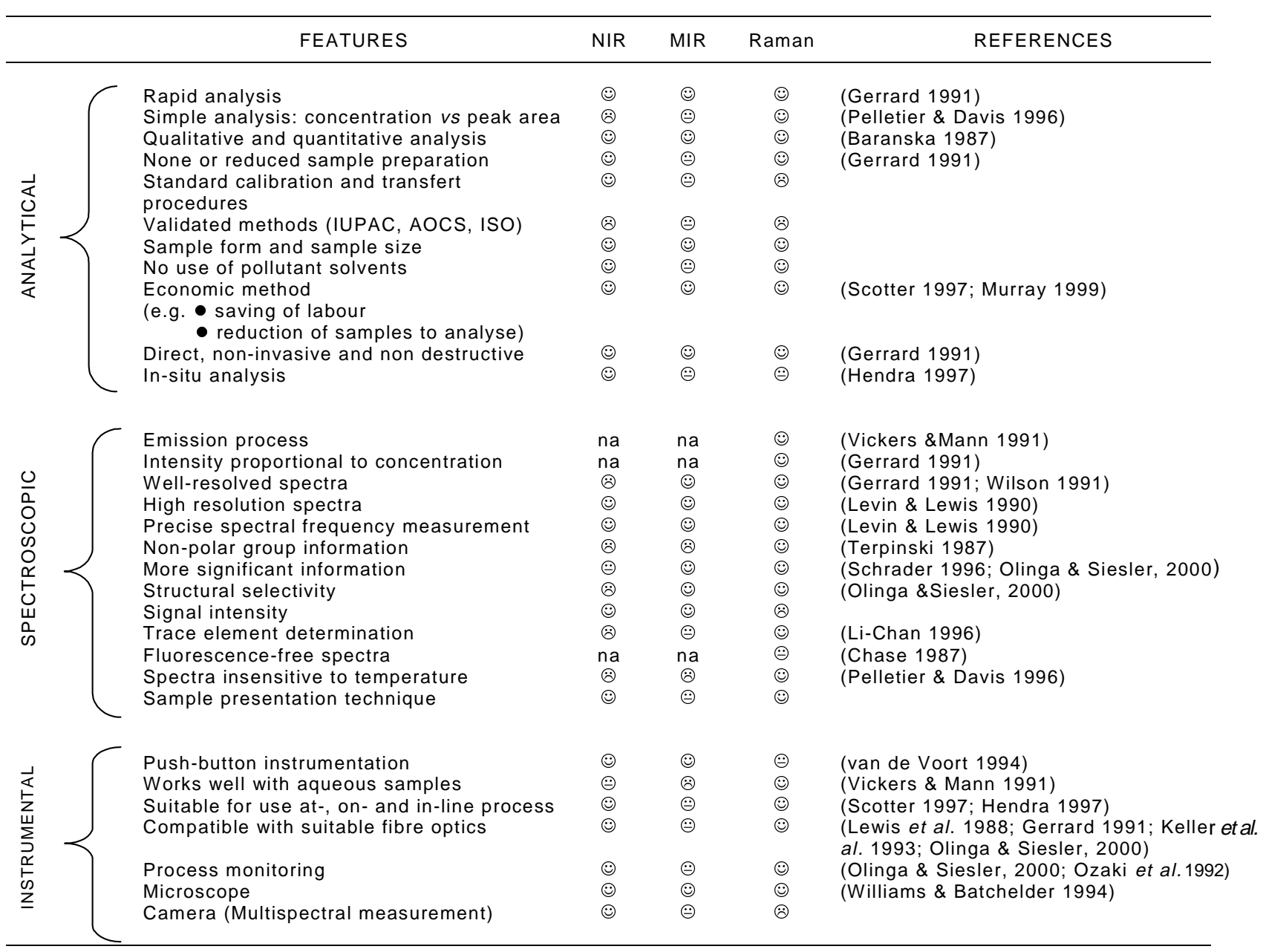

\section{WHY SPECTROSCOPIC TECHNIQUES}

The advantages of NIR, MIR and Raman spectroscopies are numerous and diversified. Table I shows the major characteristics of these techniques. Note that some of these characteristics are the same as those of other spectroscopic techniques, such as Nuclear Magnetic Resonance or Ultraviolet. The characteristics are categorised into three groups: analytical, spectroscopic and instrumental. For each characteristic and each technique, a diagram has been added to indicate whether the characteristic is an advantage $(\odot)$, a partial advantage $(\odot)$ or a disadvantage $(\odot)$. References in which these characteristics are discussed are included in the table.

\subsection{Analytical characteristics}

The analytical characteristics of NIR, MIR and Raman spectroscopies display certain advantages that make these techniques attractive as alternatives to traditional, tedious and more time-consuming analytical methods.

First, they are rapid, do not require reagents and are non-destructive. The best illustration of this is in protein analysis. The protein content of feedstuffs and foodstuffs is traditionally determined using the Kjeldhal method. With this method a single analysis of one sample takes 3 hours and requires several millilitres of different pollutant reagents (e.g., sulphuric acid) (Bertrand, 2000). Currently, with the growing concern about analysts' safety and environmental protection, laboratories try to keep at a minimum the quantity of potentially dangerous reagents used in their analyses. In addition to the health and environmental aspects of the use of these products, it is important to add the cost generated by the adequate treatment of the chemical waste. An alternative to the Kjeldahl method is the determination of protein content by NIR which takes less than a minute and does not require any 
reagents. A similar illustration can be provided with regard to iodine value determination. The time required for a single determination using a classical technique (i.e., the titrimetric or chromatographic method) is 30-60 minutes following the procedure chosen, whereas a spectroscopic determination takes about 5 minutes. Iodine value can be measured by NIR, MIR or Raman spectroscopy (Baeten et al., 2000). For the agro-food sector the speed of analysis is a crucial factor in process control where any delay in obtaining the analytical results may result in significant financial loss. The industry needs methods that produce rapid results and that allow eventually to correct the process in progress.

Other analytical characteristics of infrared and Raman spectroscopies are that they require no (or limited) sample preparation, that sample form and size are not a restriction (Williams and Batchelder 1994) and that they can be used for analysing samples in almost any physical state (i.e., solid, liquid or gas) and at any macroscopic or microscopic level. In today's world, where "instant" answers are required and nobody has the time available (or to waste) to prepare samples, there is a need for rapid methods and simple sampling techniques (Coates and Sanders 2000).

As discussed before, infrared and Raman spectroscopies are relatively economic as they are considerably less demanding in terms of time and the use of reagents than traditional methods. For research, spectroscopic methods could be also economically attractive as they allow the selection and restriction of number of samples to analyse using classical techniques. Spectra allow us explore a population before we determine what we should measure by classical technique. This is an important research characteristic of spectroscopic techniques (Murray 1999). As noted by lan Murray, "Within a closed population of 1000 samples it is valid to use spectral selection of a representative set of 100 for reference analysis, then calibrate and predict the remaining 900 , so saving $90 \%$ of the lab effort".

Additional analytical advantages of spectroscopic techniques are: (i) structural analysis is possible, in addition to qualitative and quantitative analysis; (ii) direct, non-invasive and in situ analysis can be performed. From an analyst's point of view, the main analytical drawbacks of infrared and Raman spectroscopies are that they are indirect methods, there is a lack of standardised calibration and transfer procedures, and there are few fully validated methods using spectroscopic techniques.

\subsection{Spectroscopic characteristics}

The spectroscopic characteristics listed in Table I include several spectroscopic advantages, particularities and limitations of NIR, MIR and Raman techniques. Some characteristics are common to all three techniques, whereas others are specific to only one or two of the techniques. The characteristics in common are the high resolution of the spectra obtained and the precise spectral frequency measurement that facilitates the mathematical treatment (e.g. spectral subtraction), as well as the transfer of equation between instruments. From the spectroscopic point of view, a general advantage of MIR and Raman spectroscopies is that bands are well resolved and can be assigned to specific chemical groups. There is little ambiguity in spectral assignment and quantitative analyses can be fairly component specific (Wilson 1990; Gerard 1991). By contrast, NIR spectra contain a series of successive overlapping bands which are difficult to assign to specific chemical groups. Another characteristic common to MIR and Raman spectroscopies is that they have high structural selectivity and contain more of the type of information needed in structural elucidation studies (Socrates 1994; Olinga and Siesler 2000; Schrader 1996). Both techniques can also provide information on the state of the components, such as the phase, crystallinity or conformation (Wilson 1990).

Raman and MIR spectroscopy can be applied specifically for determining trace elements. One of the best examples of this is in the measurement of carotenoid content (tenth of ppm) in food products using the Raman technique (Li-Chan 1996). The carotenoid peaks observed in the Raman spectra are not due to a Raman effect but to a resonance Raman phenomenon. An example of the MIR technique coupled with a specific extraction method is the determination of organochloride at low level in water (Acha et al. 1998).

A specific advantage of NIR and MIR spectroscopies is their good signal intensity; in Raman spectroscopy this is a limitation. Indeed, Raman scattering is a very weak phenomenon compared to the absorption observed in the two other techniques (see section 3). A specific feature of Raman spectroscopy is that it involves an emission phenomenon; Raman intensity is directly proportional to the concentration of the compound to be determined and, compared to infrared techniques, is relatively insensitive to temperature and works well with aqueous samples (Pelletier and Davis 1996).

\subsection{Instrumental characteristics}

One of the most interesting instrumental advances in spectroscopy is its potential for developing and commercialising "push-button" instrumentation. Infrared and Raman spectroscopies generally appear as sophisticated techniques for novices in the field and require a trained spectroscopist to exploit their potential in terms of 
development work (van de Voort 1994). What is required is the setting up of dedicated instruments, including the optimal sample presentation, fully programmed and precalibrated for target analysis, such that skilled, specialised operators are not crucial for the wider use of these techniques. The development of dedicated instruments in agro-food analysis has been initiated by the development of grain and powder NIR analysers and milk MIR analysers.

Another instrumental feature, making spectroscopy techniques very attractive for process control and monitoring, is the possibility of coupling the instruments with suitable fibre optics. Infrared and Raman instruments could be applied "at-line" in the laboratory control, "on-line" with the use of measurement through optically clear windows and dedicated sample techniques, and "in-line" with the use of specific probes for the measurement inside a pipe or a tank. The field of process analytical techniques is expanding rapidly due to the economic benefits achieved by using rapid and accurate information. As discussed above with regard to analytical characteristics, this will result in improved productivity and efficiency, improved quality of the transformed products and a reduction in cost and in waste products. The almost instantaneous acquisition of the analytical results allows a process to be continuously monitored, and readjusted or stopped if the desired specification is not achieved. Currently, NIR spectroscopy is overtaking MIR and Raman in this field for major technical reasons. Indeed, if NIR and Raman spectrometry can be used with relatively low-cost fibre optics of $10-100 \mathrm{~m}$ in length without severe signal attenuation, the fact that Raman measurement focuses on small sample volumes and has low sensitivity limits its industrial application. An additional limitation is the safety argument. Adapted fibre optics based on $\mathrm{ZrF}_{4}$ and $\mathrm{AgCl}$ are also available for MIR instruments but their cost, the signal attenuation and their stability restrict their use to lengths of about 1 or $2 \mathrm{~m}$, which may not be sufficient for most industrial applications (Olinga and Sielser 2000; McCreery 2000).

Over the past decade spectroscopy measurement has been extended from the macroscopic to the microscopic domain. Indeed, several manufacturers now produce NIR, MIR and Raman microscopes. These instruments have greatly extended the field of application of infrared and Raman spectroscopy. They allow the acquisition of spectra from a small sample area (a few microns) and are widely used in forensic, pharmaceutical and artwork analysis. In more recent years we have been assisting in the development of infrared camera that allows the simultaneous acquisition of thousands of spectra of an image. These developments will certainly revolutionise the analytical world of spectroscopy.

\section{SOME THEORETICAL ELEMENTS}

Generally, the theory of a technique appears forbidding, and knowledge of the theory is not essential in the application of that theory. However, a good understanding of the theory behind a technique is the best way to improve the quality of its application in research. The history of spectroscopy techniques goes back to the work of Frederick William Herschel in 1800. He discovered that the sun's energy was not limited to what we can see. He demonstrated this by projecting a rainbow onto a bench, using a prism. On the bench he positioned a series of thermometers and measured the relative heat in different parts of the rainbow. As he moved from the blue to the red, the heating effect increased and it continued to increase as he progressed to the end of the rainbow; moreover, the heating effect continued well after the end of the rainbow (Davies 1998). Herschel's work was the first step in the discovery of the electromagnetic spectrum.

The electromagnetic spectrum is usually divided into several regions, including the $\gamma$-ray, X-ray, ultraviolet (UV), visible (VIS), infrared (IR) - divided in NIR, MIR and far-infrared regions - microwaves and radio wave. Each region corresponds to a specific kind of atomic or molecular transition corresponding to different energies. Figure 1 presents part of the electromagnetic spectrum, the spectroscopic techniques concerned and the energetic transition involved. The figure also shows the wavelengths and wavenumbers associated with each region. Each part of the electromagnetic spectrum corresponds to one or more spectroscopic techniques that exploit the phenomenon which occurs when the electromagnetic radiation of a determined energy interacts with the molecule. Two complementary theories have been put forward to explain the properties of electromagnetic radiation: the classical theory (electromagnetic radiation is a wave) and the quantum theory (electromagnetic radiation is a stream of energetic particles).

\subsection{Classical theory}

Most of the properties of light can be explained by radiation with an electric field associated with a perpendicular magnetic field of high frequency that moves in the direction of the light. These fields interact with matter to give rise to a spectrum. The movement of the radiation has the properties of a sine wave described by the equation

$$
\mathrm{Y}=\mathrm{A} \sin \omega \mathrm{t}
$$




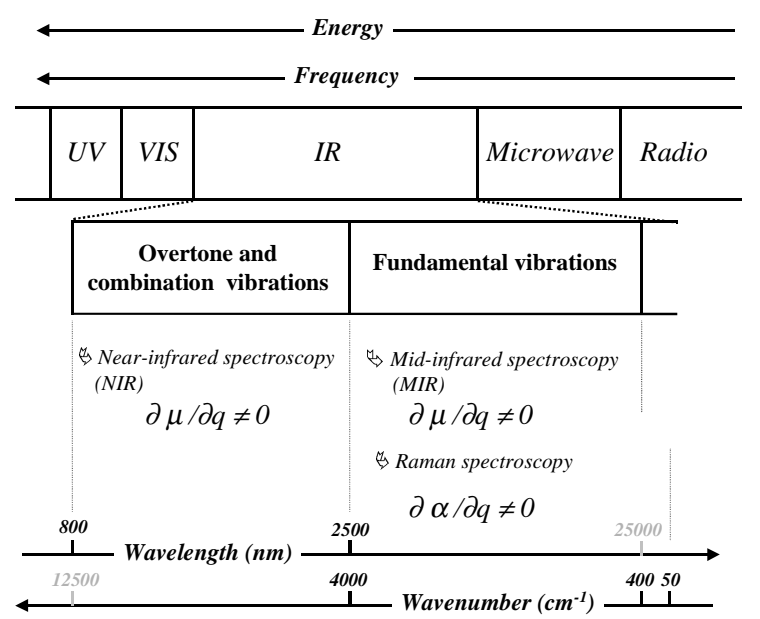

Figure 1

Several regions of the electromagnetic spectrum and the related spectroscopic techniques; the wavelength and wavenumber limits of each region are shown.

where $Y$ is the displacement with a maximum $A$ (=amplitude), $\omega$ the angular velocity rad. $\sec ^{-1}$ and $t$ is the time in seconds. In 1 second the pattern will repeat $\omega / 2 \pi$ times, referred to as the frequency $v$ expressed as cycle by second $\left(\mathrm{S}^{-1}\right.$ or $\left.\mathrm{Hz}\right)$. Equation 1 now becomes

$$
Y=A \sin 2 \pi v t
$$

Eq2

An additional property of the wave describing the movement of the radiation is the distance covered in one complete cycle known as wavelength $\lambda$. The wavelength is defined by the following equation

$$
\lambda=\mathrm{c} / v \quad \text { Eq } 3
$$

where $c$ is the universal constant of the velocity of light in vacuum. Traditionally, in NIR absorption bands are described in terms of wavelengths expressed in $\mathrm{nm}$. In contrast, MIR and Raman spectra are respectively expressed as the absorbances and the scattering intensities measured at different wavenumbers $v$ expressed in $\mathrm{cm}^{-1}$. The relationship between wavenumbers and wavelengths (taking into account the unit used) is $\bar{v}\left(\mathrm{~cm}^{-1}\right)=10^{7} / \lambda$, with the wavelength expressed in nanometers. Wavenumbers are directly proportional to frequency by the expression $\bar{v}=\mathrm{C} v$ and are easily related to the energy changes involved in transitions between different vibrational states (Osborne \& Fearn, 1986).

\subsection{Quantum theory}

The classical theory does not explain all the properties of electromagnetic radiation and its interaction with matter, and fails to account for phenomena associated with the absorption or

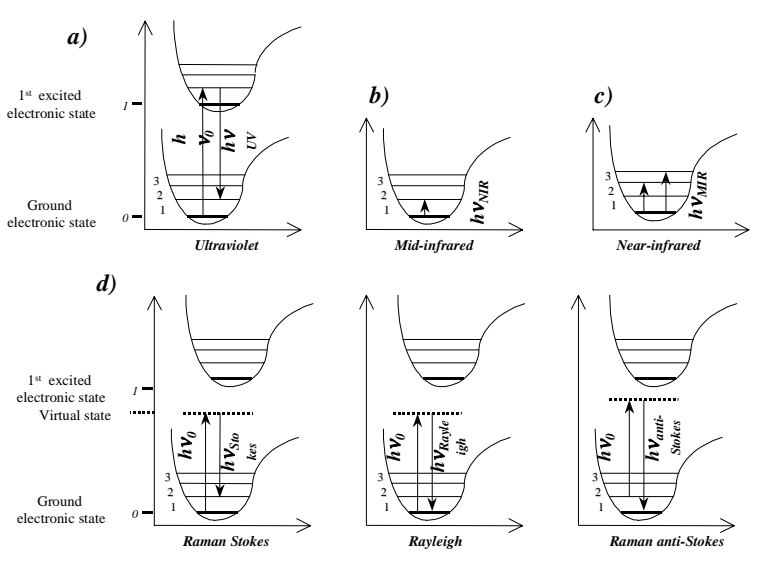

Figure 2

Energy level diagrams (Potential energy versus interatomic distance) showing the basic transitions involved in NIR, MIR and Raman spectroscopies. Two electronic states and three vibrational states are shown.

emission of energy. It is necessary to view electromagnetic radiation as a stream of discrete particles. Planck was the first to put forward the hypothesis that the electromagnetic wave was not continuous but composed of corpuscular units called quanta (Osborne and Fearn 1986). The energy of a quantum of radiation is expressed as follows

$$
E=h v
$$

Eq. 4

where $E$ is the energy, $v$ the frequency and $h$ the Planck constant. The quanta of radiation move at a constant speed and the classical equation $c=\lambda v$ is respected but the values of the energy are quantified. The energy of a quantum of radiation is defined and characterised by its frequency (Lachenal 1998).

Following this brief outline of the two complementary theories of the radiation, it is now appropriate to illustrate the different techniques discussed in this chapter. The interactions of electromagnetic radiation with molecules give rise to several spectroscopic techniques based on absorption, emission or scattering processes. NIR and MIR spectroscopies are based on absorption, while Raman spectroscopy is based on scattering process. Raman and infrared spectroscopies imply the discrete vibrational transitions that occur in the ground electronic state of molecules. It is worth noting here that a molecule is characterised by its electronic, vibrational, rotational and translational energy levels. The vibrational transitions correspond to various stretching and bending deformation modes of individual chemical bond. Figure 2 describes the different phenomena observed in the infrared regions. For the sake of simplification, only two electronic states (the ground and the first 
excited) and three excited vibrational states of each of them are shown in Figure 2.

MIR spectroscopy concerns the region of the electromagnetic spectrum lying between 4000 and $400 \mathrm{~cm}^{-1}(2500-25000 \mathrm{~nm})$. When radiation with energy corresponding to the MIR range interacts with a molecule, the energy at defined frequencies can be partially absorbed. The absorption of the incident electromagnetic radiation at a particular frequency $\left(v_{i}\right)$ is related to specific vibrational excitation energy $\left(\Delta \mathrm{E}=h v_{i}\right)$. The frequencies of these vibrations are related to molecular parameters such as bending force constants and masses of the atoms involved in this vibration. The vibrations under consideration in MIR are mostly fundamentals (i.e., from the stable vibrational state to the first excited vibrational state in the electronic ground state) (Figure $2 \mathrm{~b}$ ).

NIR spectroscopy involves radiation with energy higher than in MIR (Figure 1). The NIR region lies between 780 and $2500 \mathrm{~nm}$ (12800-4000 cm $\mathrm{cm}^{-1}$ ). Electromagnetic radiation of this region is absorbed at frequencies corresponding to overtone (i.e., corresponding to the transition from the stable vibrational state to the second [first harmonic] or the third [second harmonic] excited vibrational state, or a higher vibrational state), or a combination vibration of different vibrations of the molecule under consideration (Figure 2c).

In contrast to the two other techniques, Raman spectroscopy involves a scattering process. Briefly, Raman spectroscopy is based on the shift of an excited incident beam of radiation that results from inelastic interactions between the photons and the sample molecules. The region of the electromagnetic spectrum under consideration is similar to that in MIR (i.e., $4000-100 \mathrm{~cm}^{-1}$ ). Figure 2 presents the Raman effect via an energy level diagram. Let us consider an incident photon of energy $h v_{0}$ interacting with a molecule having vibrational energy levels $v_{1}, v_{2}$ and $v_{3}$. In scattering processes, the incident radiation interacts with the molecule that achieve a virtual (or temporary) energy level drawn in the figure as dotted line. The photon of incident energy $h v_{0}$ may proceed with unchanged energy $h v_{\text {Ray }}\left(=h v_{0}\right.$; i.e., Rayleigh scattering) or with reduced energy $h v_{\text {RST }}\left(=h v_{0}-h v_{1}\right.$; i.e. Raman Stokes scattering) or with increased energy $h v_{\text {RAST }}\left(=h v_{0}+h v_{1}\right.$; i.e. Raman anti-Stokes scattering). According to the Maxwell-Boltzmann law, only a small portion of the molecules will occupy at room temperature the first excited vibrational state $\left(v_{1}\right)$ of the fundamental electronic state. By consequence, most of the molecules are in the ground state, and the Raman Stokes scattering bands are more intense than the anti-Stokes Raman scattering bands (Baranska 1987; Diem 1993; McCreery 2000). Many studies conducted with Raman spectroscopy involve Stokes Raman measurement.

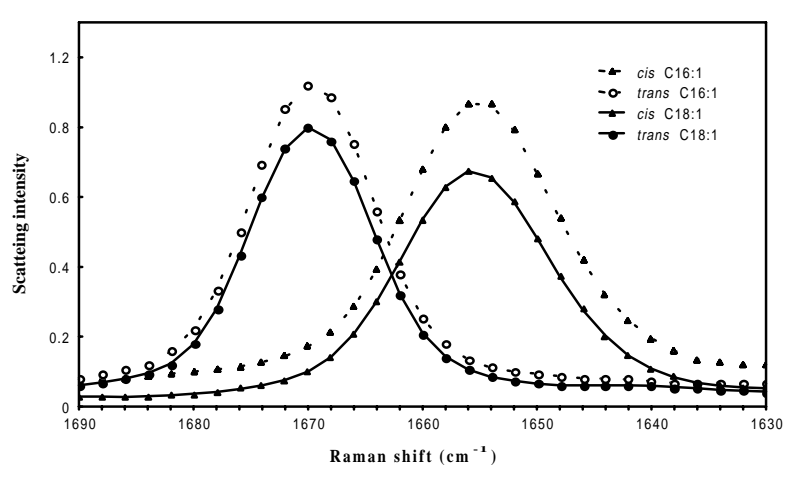

Figure 3

FT-Raman spectra of various pure fatty acid methylesters. Scattered band observed in the vicinity of $1660 \mathrm{~cm}^{-1}$ characteristic of the $\mathrm{C}=\mathrm{C}$ vibration of $\mathrm{RCH}=\mathrm{CHR}$ groups.

\subsection{Absorption and scattering: band position and intensity}

The so-called selection rules dictate the probability of excitation of a particular vibration frequency. The selection rules determine the number of vibrational bands in infrared absorption spectra and in Raman scattering spectra. These rules are derived from the application of group theory to atomic vibrations of the molecules belonging to different classes of symmetry. Several factors determine the vibration frequencies, including: the inter-atomic distances, the spatial arrangement of the groups, the Fermi resonance, the physical state of the sample, the polarity of the environment and the formation of hydrogen bonds.

Figure 3 illustrates the influence of several factors on the band position observed in FT-Raman of different pure fatty acid methylesters (palmitic, C16; stearic, C18; palmitoleic, cis c16:1; oleic, cis C18:1; palmitoelaidic, trans $C 16: 1$ and elaidic, trans $C 18: 1$ acids). The trans fatty isomers have the band of $\mathrm{C}=\mathrm{C}$ stretching vibration at a wavenumber higher than the equivalent of cis isomers (Aparicio and Baeten, 1998).

Infrared absorption requires a change of the intrinsic dipole moment with the molecular vibration. In contrast, Raman scattering arises from the change in polarizability of the electron distribution in the molecules as it vibrates (Grasseli and Bulkin 1991). Raman band intensity is proportional to the expression $(\partial \alpha / \partial Q)^{2}$ where $\alpha$ is the polarisability and $Q$ the normal co-ordinate of the group of atoms of interest. Infrared band intensity is proportional to the expression $(\partial \pi / \partial Q)^{2}$ where $\pi$ is the induced dipole moment of the molecule. This explains why the same molecule may give infrared and Raman bands with differing intensity and band shape (Baranska et al. 1987). 


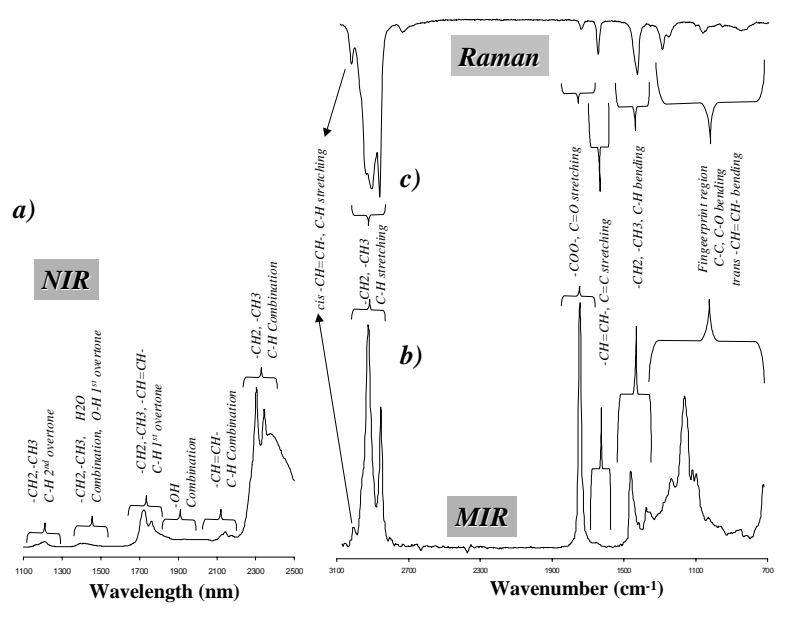

Figure 4

Near-infrared (inverse scale) (a), mid-infrared (b) and Raman (c) spectra of a vegetable oil. The NIR spectrum is plotted as the absorbance versus the frequency $(\mathrm{nm})$, Raman spectrum as the scattering intensity versus Raman frequency $\left(\mathrm{cm}^{-1}\right)$ and MIR spectrum as absorbance (Log1/R) versus frequency $\left(\mathrm{cm}^{-1}\right)$. The NIR spectrum was obtained by reflection mode while Raman and MIR (with ATR accessory) spectra using FT instruments.

\section{SELECTING THE INFORMATION}

Figure 4 presents the (a) NIR, (b) MIR and (c) Raman (reverse scale) spectra of a vegetable oil. The attribution of the most noteworthy bands is given. Note the complementarity of the spectroscopic techniques from the chemical point of view. A brief description of the band is given here. For a more detailed description of the different spectra, and of the attribution of the bands in fats and oils, readers are referred to the literature (Socrates 1994; Baeten et al. 2000).

The MIR spectrum (Figure $4 \mathrm{~b}$ ) of a vegetable oil or fat contains well-defined peaks, mainly in the $3100-1700 \mathrm{~cm}^{-1}$ region, and overlapping peaks in the fingerprint region between 1500 and $700 \mathrm{~cm}^{-1}$. As described earlier, this region of the electromagnetic spectrum contains mainly fundamental vibration bands when the vibration induces a change in the dipole moment of the molecule under consideration. From high to low wavenumber, we have at around $3000-2800 \mathrm{~cm}^{-1}$ a group of peaks of $\mathrm{C}-\mathrm{H}$ stretching vibration, near $1745 \mathrm{~cm}^{-1}$ a single peak being the $\mathrm{C}=\mathrm{O}$ stretching vibration of carbonyl groups, in the $1400-1200 \mathrm{~cm}^{-1}$ region the bending vibration band of $\mathrm{CH}_{2}$ and $\mathrm{CH}_{3}$ groups, and in the 1125-1095 $\mathrm{cm}^{-1}$ region the bands characteristic of stretching vibration of $\mathrm{C}-\mathrm{O}$ and $\mathrm{C}-\mathrm{C}$ groups. In addition to this information, MIR spectra can also provide information on the state of the components such as the phase, crystallinity and conformation (Wilson 1990). The main spurious bands observed in MIR spectra are those of $\mathrm{CO}_{2}$ and water vapour. For tables regrouping the band position of the different groups, readers are referred to Socrates (1994).
As in the MIR region, the Raman spectrum of a vegetable oil (Figure 4c) contains well-defined bands. Whereas the band position is quite similar for both regions, the relative intensities of the bands are very different. For instance, the carbonyl band near $1745 \mathrm{~cm}^{-1}$ is intense in MIR spectroscopy but weak in Raman spectroscopy. In contrast, the band near $1660 \mathrm{~cm}^{-1}$ of $\mathrm{C}=\mathrm{C}$ groups is very weak in MIR spectroscopy but intense in Raman spectroscopy. As in MIR spectra, Raman spectra also contain information on the state of the components.

Figure $4 a$ presents the NIR spectrum of a vegetable oil. NIR spectra show various overlapping bands. As seen before, these bands are the result of the first and second overtones, as well as of the combinations of two or more fundamental vibrations that occur in the MIR region. From low to high wavelengths, the region characteristics are: the second overtones of C-H groups (1050-1250 nm), the combination band of $\mathrm{C}-\mathrm{H}$ groups $(1300-1450 \mathrm{~nm})$ and the first overtone of $\mathrm{CH}=\mathrm{CH}(1600-1800 \mathrm{~nm})$, the $\mathrm{OH}$ combination band (1880-1930 nm), and the $\mathrm{CH}$ combination bands $(2100-2400 \mathrm{~nm})$.

\section{SPECTROSCOPIC INSTRUMENTATION}

The field of instrumentation in infrared and Raman spectroscopies is constantly evolving. This evolution has been rapid, for instance, in process analytical chemistry which is critical for the pharmaceutical, chemical and agro-food industries, among others. A general trend is that the analysis is moving closer to the sampling point by means of fibre optics allowing real time analysis and continuous control of processes. Another trend is the development of analytical chemistry systems combining the instrument, the interface between the instrument and the sample (i.e., sample presentation technique) and the software integrating data acquisition, chemometrics and data archiving for specific application (Ciurczak 1991). These systems are usually called dedicated instruments.

In addition, with the introduction of hyphenated techniques such as infrared microscopy, the application of spectroscopic techniques extends from macroscopic analysis to microscopic analysis. These and other developments enable infrared and Raman spectroscopy to be applied to more and more analytical challenges. In the following sections, the main instrumental characteristics are described for each of the techniques covered in this chapter. As mentioned earlier, special emphasis has been placed on the instrumentation used (or that could be used) in fat and oil analyses.

\subsection{Near-infrared instrument}

Various classifications exist to describe the NIR spectrometers. One of them classifies the 
instruments into three groups according to the instrumental device: (i) sequential instruments, where the absorbances are collected sequentially in the time (in this group are the instruments equipped with a monochromator or filters); (ii) multiplex instruments (FT), where the detector simultaneously receives information from several frequencies; and (ii) multichannel instruments, with several detectors that separately record the absorbances at several wavelengths. Another classification takes into account the dispersive or non-dispersive properties of the instrument. With a dispersive instrument, the frequencies are spatially separated by means of an appropriate device such as a prism or a monochromator. In contrast, the main feature of non-dispersive instrument is the use of interferometry technology (Bertrand 1998).

\subsubsection{Classical instrument}

Most of the instruments used in agro-food analysis are sequential instruments equipped with a monochromator or a filter wheel as a wavelength selector. Figure 5 shows the instrumental configuration of these instruments working in transmission or reflection mode. Briefly, a spectrophotometer includes a polychromatic radiation source (e.g., a tungsten-halogen lamp), a wavelength selector, a sample compartment and the detector. The wavelength selector could be a monochromator, a filter wheel, an acoustico-optic tuneable filter (AOTF) or an interferometer. A monochromator disperses the radiation according to wavelength. Holographic grating is the most popular dispersion element used. The filter wheel is a device allowing the sequential bands determined by the interference filter. The wheel usually holds between 3 and 20 filters. The AOTF technology is based on a monocrystal of Tellurium dioxide $\left(\mathrm{TeO}_{2}\right)$ coupled with a thin piezo-electric monocrystal plate. AOTF is based on the modification of the refraction index of matter by means of radio frequency effect. When a high-frequency electric field is applied, the piezo plate generates a high-frequency acoustic wave propagating in the crystal. If NIR radiation is beamed simultaneously with the acoustic wave onto the face of the crystal, both will interact and part (i.e., band with a determined wavelength) of the incident radiation will be refracted. With a change in the high electric field applied to the piezo-plate, the band with the position of the transmitted light is shifted. Other dispersive instrumental devices include the use of several light emitted diodes (LED) as a light source in the spectrometer. With such a system each LED is successively activated and the respective absorbances measured. The instruments based on AOTF or LED technology have the advantage of not including moving parts and are quite robust for industrial application.

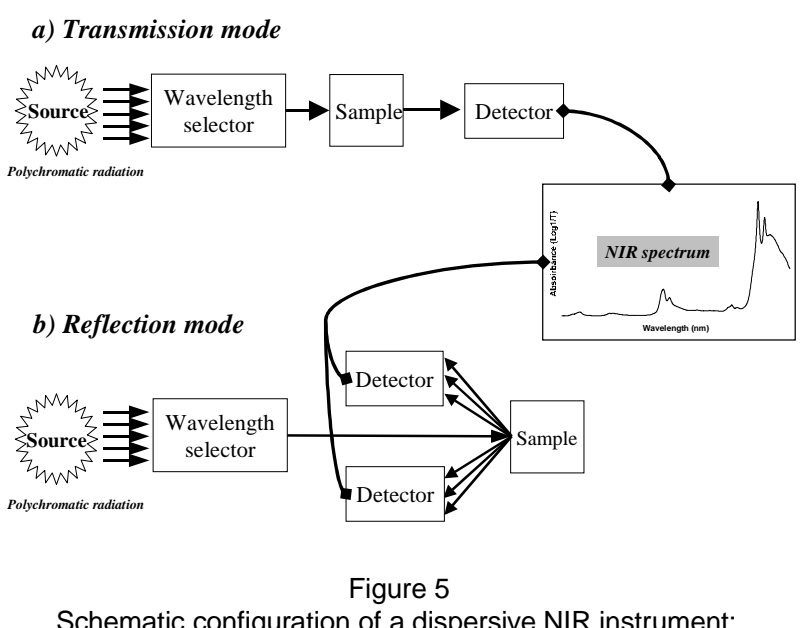

Schematic configuration of a dispersive NIR instrument; (a) transmission mode and (b) reflection mode.

In addition to the instruments described above, there is multichannel detection using diode array technology. With such an instrument, several detectors are used and can record simultaneously the reflected light. For example, a Corona-Zeiss instrument adapted on an experimental hopper developed and designed at CRAGx to simulate the flux of a harvester, or a Perten instrument used to measure fruit and meat products. These instruments are used at CRAGx to measure the quality of grain or forage in the field (Sinnaeve et al. 2000) and to check the quality of fruit (Moons and Dardenne 2000) as well as the authenticity of farmed chicken (Fumière et al. 2000). In the first study the instrument is placed on the harvest engine, while in the two others the fruit or the entire chicken is placed below the instrument. Concurrently, there is also a trend towards the miniaturisation of the instrument.

\subsubsection{Microscope and camera}

All the instruments presented hitherto are used to analyse large volumes of samples with a macro sampling configuration. In the past 20 years, spectroscopic techniques have been used in the analysis of much smaller micron-sized samples using optical microscopes interfaced with existing spectrometers (Williams and Batchelder 1994). In forensic analysis, infrared microscopy has become a standard laboratory procedure. An important factor is the ability to record visual images of the sample and to link these to the infrared signature of the sample at a specific location. However, it is important to remember that infrared and Raman microscopies are still microscopic and by nature require a degree of expertise for good sample preparation and data acquisition procedures (Coates and Sanders 2000).

Several companies active in NIR instrumentation produce NIR microscopes. These instruments allow spectra to be collected from extremely small samples 


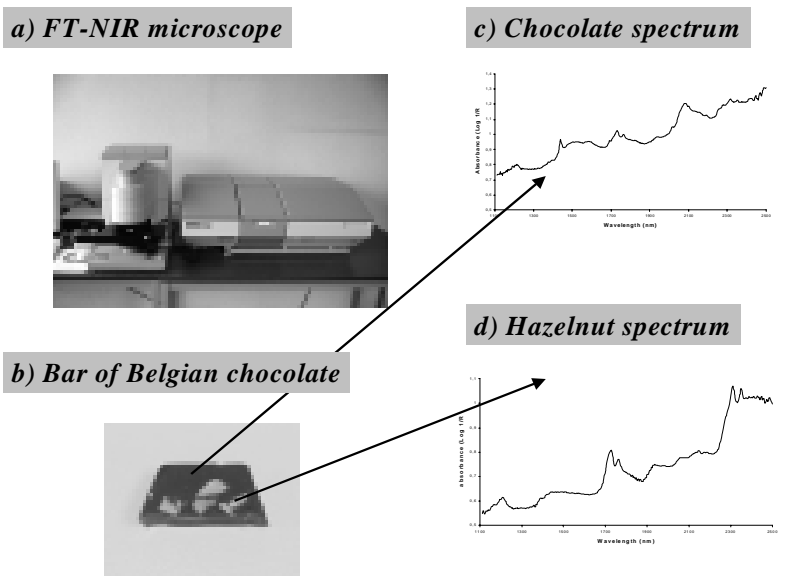

Figure 6

Perkin-Elmer FT-NIR microscope (a) and Visible image of the cross-section of a bar of Belgian chocolate with hazelnut pieces (b). Spectra of chocolate (c) and the hazelnut (d).

$(5 \mu \mathrm{m} \times 5 \mu \mathrm{m})$. Usually, the instrument includes a camera and a viewing system for magnifying the visible light image of the sample so as to observe, identify and isolate a point of interest. For example, Perkin-Elmer FT-NIR microscope (Figure 6) is used at CRAGx to detect meat and bone meal particles in feedstuffs (Piraux and Dardenne 1999).

The infrared microscope can be used to take spectra from a variety of sample points from an inhomogeneous surface (for instance, a variety of flour particles) and produce an infrared map. The procedure used is called mapping and is very time consuming because the measurement has to be done point by point. In recent years, the introduction of the multichannel spectrometer has been made more efficient and allowed the simultaneous acquisition of spectral data from several points. With multichannel instruments, several photoelectric detectors are used and allow a simultaneous recording of the reflected or transmitted light corresponding to several points. Basically, there are systems involving a line-scan camera or a matricial camera (two-dimensional detector).

\subsubsection{Sample presentation}

The presentation techniques used in NIR spectroscopy are numerous and depend on the transmission and reflection mode or the state of the sample analysed (gas, solid or liquid). For liquids such as oils, special reflection and transflexion cells are designed for the reflection mode. For the transmission mode, there are specially designed quartz cuvettes or flow cells. These devices are very attractive for analysing oils and fats as they can be thermostatised. Usually, these cells have a path length of 0.5 or $1 \mathrm{~mm}$. A greater path length would lead to saturation of the detector except in the near

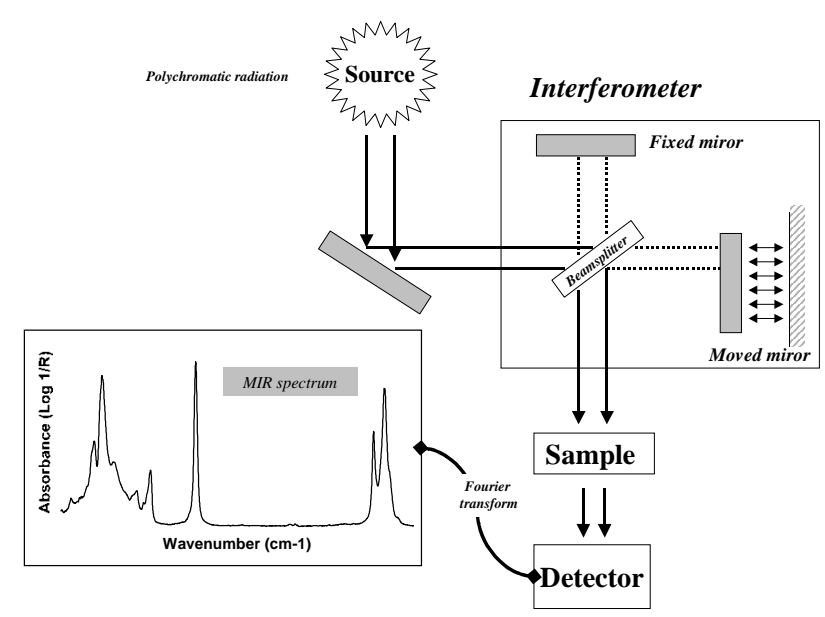

Figure 7

Schematic configuration of an FT-MIR instrument.

near-infrared (800-1100) where the path length can reach $2-3 \mathrm{~cm}$. For the reflection mode and for solid fat samples such as butter and margarine, there is aluminium cup covered with a quartz window.

\subsection{Mid-infrared instrument}

The first generation of MIR spectrometers used a high-resolution diffraction monochromator and has been used mainly for qualitative analysis such as the identification of chemical compounds. The quantitative application of these instruments has been limited. In early 1970 the MIR instruments underwent an important revolution with the development of commercial spectrometers using interferometry technology. This revolution sparked a renewed interest in this technique (Wilson and Tapp 1999). Figure 7 presents the schematic diagram of an FT-MIR instrument.

An interferometer consists of two perpendicular mirrors, one is stationary, while the other moves at a constant velocity. Between these mirrors there is a semi-reflector (also called beam-splitter). The beam enters the interferometer, hits the beam-splitter and is divided into two beams. One beam is reflected onto the fixed mirror and the other onto the moving mirror where they are reflected to be recombined at the beam-splitter. The two beams undergo constructive and destructive interferences due to the path difference between the two mirrors (Griffiths 1972; van de Voort 1994; Diem 1993). The recombined radiation is directed to the sampling compartment where it will interact with the sample. The transmitted, diffused or reflected light is pointed at the detector where fluctuations in the intensity of the energy are digitised, resulting in an interferogram that contains the spectral information related to the sample. The interferogram is the intensity of energy measured versus the position of the moving mirror 
(time domain) and is converted into a conventional infrared spectrum (frequency domain) by the mathematical operation known as the Fourier transformation. Thus, spectroscopy using interferometry is also called Fourier transform (FT) spectroscopy.

There are several advantages of interferometry technology. First, interferometers have a higher spectral optical conductance (or optical efficiency) than the grating spectrometers (i.e., instrument using the monochromator technology). This characteristic is called the Jacquinot's advantage. Second, there is the Felgett's advantage (also called the multiplex advantage), which emphasises the efficiency of the interferometer in using the light entering it. The third advantage is that the frequency scale is generated from a He-Ne laser, the wavelength of which does not vary and is known precisely. This enables spectra to be superimposed exactly and added. This is called the Connes' advantage (Wilson, 1990; Chase, 1987; Hendra et al., 1993).

\subsubsection{Microscope and camera}

As discussed in the NIR instrumentation section, joining light microscopy with infrared spectroscopy allows scientists to resolve the chemistry of microscopic domain. In 1980, the commercial MIR microscope became available. By late 1980, 4000 FT-MIR microscopes were in use in a variety of fields, including the analysis of forensic trace evidence, the detection of microscopic contamination in drugs, and the analysis of defects in industrial products (e.g., fibre coatings) (Wetzel and Reffner 2000). In the past few years MIR cameras have come onto the market, but their application in agro-food analysis has not been investigated.

\subsubsection{Sample presentation}

Concurrently with the development of FT instruments, the development of adequate sampling presentation techniques for the MIR region has contributed to the renewed interest. Indeed, the improved performance of FT-MIR instruments made it possible to design sampling accessories that were difficult to implement using older instruments. Initially, the sample presentation techniques included fixed path length transmission cells, coated or smeared films on windows, hot-pressed films and alkali halide pellets (KBR) were used.

Now there are more user-friendly sample presentation techniques for MIR. Possibly the most interesting development is the introduction of simple reflectance techniques that include specular reflectance for solids (e.g., powder), attenuated total reflectance (ATR) for liquid or slurries. As this chapter focuses on the analysis fat and oils, the ATR technique is outlined here as it is aimed at liquids and a)

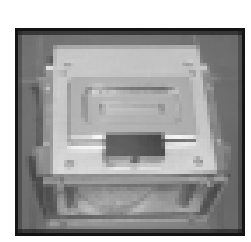

b)

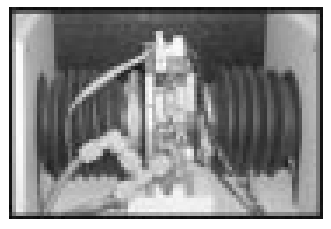

c)

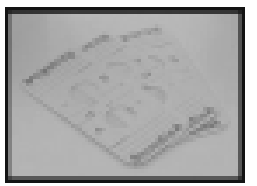

Figure 8

Several sampling devices used in MIR spectroscopy. a) ATR, b) Thermostatised flow cell, c) IR-card.

slurries. In ATR, the sample with a refractive index is in contact with a crystal (also called internal reflection element [IRE]) with a higher refraction index and with a weak infrared absorption in the region of interest. The radiations are combined in the IRE and reflected on its inner surface. At each reflection, a standing evanescent wave exists and part of the radiation energy penetrates a short distance into the sample and interacts with it. The penetration depth of the radiation depends on the incidence angle, the refractive index of both materials (crystal and sample) and the wavelength (Harrick 1967). Several varieties of ATR exist: cylindrical ATR, squarecol ATR and horizontal ATR. The first two have an effective surface several times greater than the third (Harrick 1967; Afran 1993). For fats and oils we have thermostatised flow cells and ATR cells that could be coupled with an appropriate pump. Other sampling accessories sucha IR-card in polyethylene can be used with success in analysis of fats and oils. Figure 8 shows different sampling techniques that can be used in MIR spectroscopy.

\subsection{Raman instrument}

In the past two decades, Raman instrumentation has changed a lot. Indeed, with the introduction in 1986 of the near-Fourier transform (FT) Raman spectrometer including the charged coupled device, the use of diode lasers emitting in the NIR range and holographic optics have led to a resurgence of interest in this technique in agro-food analysis (Chase 1987). There are two fundamentally different designs of the Raman spectrometer: dispersive or non-dispersive. There are many problems associated with dispersive instruments, such as fluorescence interference, photodecomposition of the sample, wavenumber calibration problems, lack of precise frequency base from scan to scan, and difficulty in attaining high-resolution spectra (Chase 


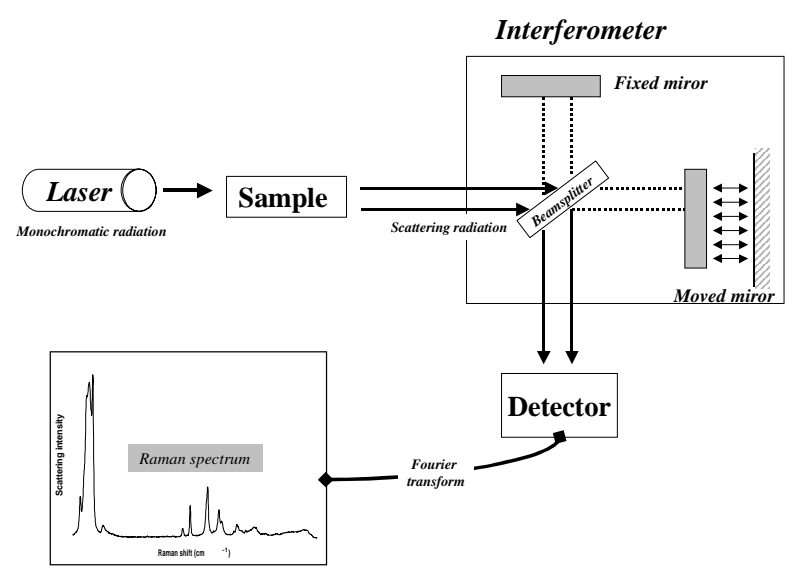

Figure 9

Schematic configuration of an FT-Raman instrument.

1987). The main difficulties in the fats and oils analysis with classical dispersive Raman spectrometers are caused by the fluorescence due to sample impurities, specifically the carotenoid content (Levin and Lewis, 1990; Sadeghi-Jorabchi et al. 1990). As the non-dispersive spectrometer seems better with regard to the analysis of fat and oils, only this instrument will be discussed here (Diem 1993; McCreery 2000). Figure 9 presents a schematic non-dispersive NIR FT-Raman spectrometer.

In a near-FT-Raman spectrometer, a laser (monochromatic beam emitting in the NIR range) is directed with mirrors onto the sample. The incident photons interact with the samples and scattered light is collected by adapted optical devices and directed to the interferometer. The modulated beam reaches the detector and the Raman spectrum is obtained by the application of Fourier transformation on the signal (i.e., interferogram) measured at the detector. Note that in an FT-Raman instrument the interferometer is placed after the sample, while in an FT-MIR instrument it is located before the sample. The advantages of interferometry discussed earlier in relation to MIR instruments are also valid for FT-Raman instruments.

\subsubsection{Microscope and camera}

As in the case of NIR and MIR spectroscopy, Raman spectroscopy can be used for the analysis of very small samples or small heterogeneities in larger samples. This potential was first demonstrated in 1975 by Rosco and colleagues (ref. cited by Williams and Batchelder 1994). In fact, the ability of Raman spectroscopy to utilise conventional glass optics made it possible to interface a classical Raman spectrometer with an optical microscope. In comparison with the instruments discussed earlier, the Raman spectrometer used in Raman microscopy generally has an emitting source in the visible range.
Current Raman microscopes are able to analyse samples down to $1 \mu \mathrm{m}$ in diameter, making this technique very attractive for micron-sized studies. The ability of this technique to obtain the vibrational fingerprint of fundamental vibrations from a micro-scale sample or from an impurity in a large matrix is also a decisive factor in its application in research and industrial laboratories (Williams and Batchelder 1994). The examples of applications of Raman microscopy are numerous. For instance, it is used in the analysis of small impurities in pharmaceutical tablets, polymer film, minerals, human dentin and resin composites, carbon fibre and micro-organisms (McCreery 2000). In addition, the observation of very weak water bands in Raman spectroscopy enables the recording of spectra from aqueous phase media and permits the application of Raman microscopy to the analysis of in situ cells such as human tissue (McCreery 2000) or vegetable products (Manfait et al. 1999).

Raman microscopes can be used to produce a Raman map of a sample by the successive acquisition of the spectra from several points. This process of mapping has been made more efficient by using $2 \mathrm{D}$ detectors and collecting line images or global images. Raman line and global imaging have been used for the study of products as different as semiconductors or human lymphocyte (McCreery 2000).

\subsubsection{Sample presentation}

Raman spectroscopy in chemical analysis combines many of the advantages of MIR and NIR spectroscopy. As discussed earlier, MIR and Raman spectroscopies concern the fundamental vibrations with high spectral resolution. On the other hand, sampling in NIR and Raman spectroscopies can be very simple (Bailey et al. 1967). The Raman spectra of samples contained in glass (NMR tube or trial tube) or plastic vials can be easily obtained without sample preparation. Care needs to be taken for the variation (e.g., in thickness) between sample containers. Also, spectra from very small quantities (as small as $1 \mu \mathrm{l}$ of solution or $1 \mathrm{mg}$ of solid sample) can be obtained (LiChan, 1996). As for NIR, low-cost optical fibres can be used.

The development of NIR, MIR and Raman instrument is closely linked to the calculation capacity of today's computers, as well as to the widespread use of mathematical and statistical procedures. In fact, according to the complexity of the structural attribution of absorption and scattered bands, as well as the high quantity of data rapidly generated by spectroscopic techniques (usually several hundreds or thousands of data with high correlations obtained in a few seconds or minutes), mathematics and statistics are unavoidable (Martens and Naes 1989; Williams and Norris 1987). The "chemometrics" term regroups the mathematical and 
statistical approaches that are especially suitable for handling the large datasets produced by modern analytical methods such as infrared and Raman spectroscopies. Such data contain a large number of discrete points. In general, there are more data points per observation than there are observations (Kemsley 1996; Fearn 2001). Today, the research activities in chemometrics are very intense and a significant proportion of publications dealing with spectroscopy focus on this field.

In infrared and Raman spectroscopy, the analytical problems addressed by chemometrics tend to fall into two classes: qualitative analysis and quantitative analysis. Although some of the chemometric techniques used in spectroscopy overlap the two classes partially or totally, each of them corresponds to two main varieties of algorithms: discriminant algorithms for the qualitative analysis and multiple regression algorithms for quantitative analysis (Howard 1989; Brown 1995; Aparicio 2000; Dardenne et al. 2000). As there is a special chapter on chemometrics in the book, this topic -unavoidable with spectroscopic methods- is not developed.

\section{APPLICATIONS}

Various books and papers have reviewed the application of near-infrared (NIR) (Baeten et al. 2000; Riaublanc et al. 2000), mid-infrared (MIR) (Wilson 1990; van de Voort and Ismail 1991; van de Voort 1994; Wilson and Tapp, 1999; Baeten et al., 2000; Riaublanc et al. 2000; Bertrand and Dufour 2000) and Raman spectroscopies (Ellis et al. 1989; Li-Chan 1996; Keller et al. 1996; Baeten et al. 2000) in the analysis of agro-food and lipids. The following sections summarise the potential and the trends in lipid analysis (quantitative, qualitative, process monitoring).

\subsection{Quantitative analysis}

\subsubsection{Determination of fat content}

Infrared techniques are widely used to determine the main constituents of agro-food and feed products. For instance, NIR spectroscopy can be applied to determine the fat content of agricultural products such as cereals, foodstuffs such as butter, milk, flour or meat products, and feedstuffs such as fish meal or pet food (Sinnaeve et al. 1990; Chevalier et al. 1990; De Pedro et al. 1992; Panford and de Man 1990; Garcia-Olmo et al. 1998; Laporte and Paquin 1999). As discussed earlier, this technique can be used to determine the constituents of a wealth of varieties of samples, whether liquid or solid, ground or whole.

One of the trends is the development of networks of infrared instruments. Worldwide, there are private and public networks of NIR instruments for analysing cereals, forage or other agro-food products. In this structure, a mathematical model is developed in one laboratory and has to be transferred to the different partners of the network (Dardenne and Biston 1991; Bouveresse et al. 1994; Dardenne and Welle 1998; Duponchel et al. 1999). The Agricultural Centre of Gembloux is charged with the management of this network by Provimi Research and Technology Centre. The network includes 12 feed factories equipped with NIR spectrometers and spread out across the world. The advantage of a network is the saving of time and cost by the reduction of samples to analyse using the classical technique, as well as the acquisition of very robust calibrations (regression models). Among the limitations of such a structure are the need to standardise the different instruments of the network to facilitate the smooth transfer of data between them and the need to standardise the references laboratories of the network.

The ultimate evolution of the network is the use of Internet facilities to manage it. In a classical network, the different spectrometers are standardised and hold the global equations of the network to predict unknown samples. In a network using Internet facilities, the spectrometers are also standardised, but the equations are stored by a common server. To predict an unknown sample, the spectrum is sent via the Internet to a server were the equations are stored. There, the determination of the selected component is done and the result is sent by electronic mail to the laboratory. The great advantage of such a procedure is the ease of managing the different equations of the network because updates of equations need to be done only on the server and not on each spectrometer, as in the case of a classical network. An additional advantage is the

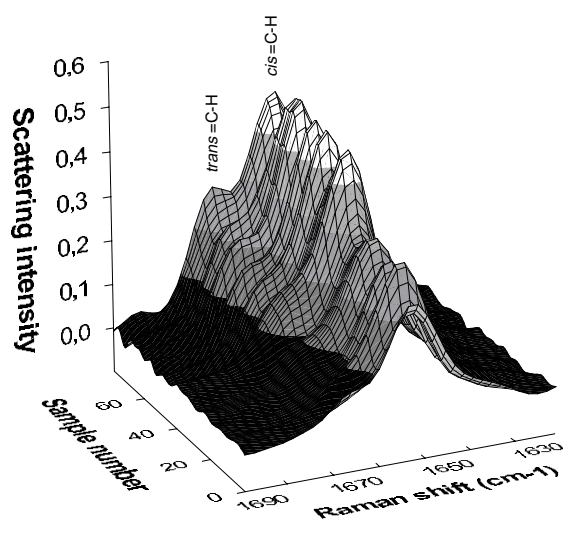

Figure 10

Raman scattering bands observed in the vicinity of $1630-1690 \mathrm{~cm}^{-1}$. Spectra of milk anhydrous fat having a trans content between 0.5 and $12 \%$. 
high flexibility of such a procedure where a laboratory that has to analyse an unusual product can check the server to see whether the equations for this product had been developed for another laboratory of the network. The main drawback of the use of the Internet is the need of permanent connection. But batch mode can be used.

Mid-infrared spectroscopy is also widely used to determine the fat content of high fat products such as butter and margarine or milk products. The dairy industry uses MIR spectrometry in routine analysis and the official control laboratories make the analysis with this kind of instrument (Wilson 1990; van de Voort et al. 1992, 1993).

\subsubsection{Determination of major and minor components in lipid}

The demonstration of the potential of IR and Raman spectroscopies for the determination of various chemical compounds and chemical indexes have been done. Briefly, the different determinations are: (i) the unsaturation degree known as iodine value (NIR: Hourant et al. 2000; MIR: Afran and Newbery 1991; van de Voort et al. 1992b; Sedman et al. 2000; Raman: Sadeghi-Jorabchi 1990; Baeten et al. 1998); (ii) the trans and cis content (NIR: Li et al., 2000; MIR: Belton et al., 1988; Ulberth and Haider 1992; Sedman et al. 1997; van de Voort et al. 1995; Mossoba et al. 1996; Degreyt et al. 1998; Adam et al. 1998, 1999; Favier et al., 1996; Alonso et al. 2000; Raman: Bailey and Horvat 1972; Sadeghi-Jorabchi et al. 1991); (iii) the saponification number (MIR: van de Voort et al. 1992; Li et al. 2000); (iv) the solid fat index (MIR: van de Voort et al. 1996); (v) the free fatty acids (MIR: Lanser et al., 1991; Ismail et al. 1993); (vi) the peroxide and anisidine values (MIR: van de Voort et al. 1994; Dubois et al. 1996; Ma et al. 1997, 2000). Near-infrared spectroscopy is also used to analyse the fatty acid profile of high-fat products Alonso et al. 2000). Figure 10 shows the Raman scattering bands observed in the $1630-1690 \mathrm{~cm}^{-1}$ region of milk anhydrous fat having a trans content between 0.5 and 12\% (Baeten, V., Meurens, M.; Larondelle, Y. and Dardenne, P., Unpublished results). Today the trend lies in the development of validated spectroscopic methods based on internationally accepted guidelines. Various collaborative studies of spectroscopic methods have been published (Adam et al. 2000; Cox et al. 2000).

Fulfilling certain experimental and sampling criteria, spectroscopic techniques can be used to analyse minor compounds. This is particularly true for Raman spectroscopy, although the development of extractive methods for MIR facilitates the detection of compounds at a very low level (Acha et al. 1998; Yang and Huan 2000). The sensitivity of a conventional Raman analysis is usually at the percent level. However, by creating certain response conditions with the laser wavelength used to illuminate the sample, analytical sensitivities can be determined at the ppm and pbb levels (Williams and Batchelder 1994; Keller et al. 1993; Schrader 1996). These sensitivities are due to the Raman resonance phenomenon and not to the classical Raman phenomenon that occurs in Raman experiments. Resonance Raman spectroscopy has been applied to analyse selectively trace components such as pigments (Merlin et al., 1994; Ozaki et al., 1992), cholesterol (LeCacheux et al. 1996) and vitamin A. Another way to obtain an enhanced Raman signal is to use surface-enhanced Raman spectroscopy (SERS) (Dou et al. 1999). In SERS, the analysed molecules are adsorbed onto a microscopically roughened metal surface and the Raman measurement is then made. Surface enhancement spectroscopy has been applied successfully to lipids (Saint-Pierre Chazalet 1994; Weldon et al. 1998).

\subsection{Qualitative analysis}

The role of the analyst in the agro-food sector is evolving rapidly. One trend is the shift of interest from compositional legislation to label declaration. Thus, the authentication of agro-food products has become a crucial issue over the past decade (Simpkins and Harrison 1985; Dennis and Ashurst 1996). Authentication is usually defined as the assessment of a product to ensure that it conforms strictly with the description provided by its label and complies with the legislation in force in the country in which it is marketed or sold (Martin 1996; Aparicio et al. 1996; Lees 1998; Aparicio 2000). Authentication is of paramount importance both for official bodies in charge of the control of labelling and for the industry where incoming batches of raw materials and finished products must be tested for compliance with specifications. Spectroscopic techniques are widely used to tackle authentication challenges. The fact is that infrared and Raman spectroscopy can provide in a few minutes spectral signatures that can be used as a fingerprint of the agro-food products. Table II summarises some of the papers showing the potential of NIR, MIR and Raman spectroscopy in authentication. The table is not exhaustive, but presents the various agro-food products analysed, the main issues and the spectroscopic method used in the references listed.

Different features can be extracted from the references listed in Table II. First, the studies can be classified according to whether real or artificial samples were used. Second, two strategies to demonstrate the potential of the techniques were used. (i) Some of the works are based on the analysis of a sample set (usually several tenths) of authentic and adulterated samples and use different chemometric tools to demonstrate the potential of spectroscopic techniques. (ii) In contrast, other 
Table II

Review of papers on the authentication of food products using infrared (NIR, MIR) and Raman spectroscopy. (Modified from Baeten \& Aparicio 2000)

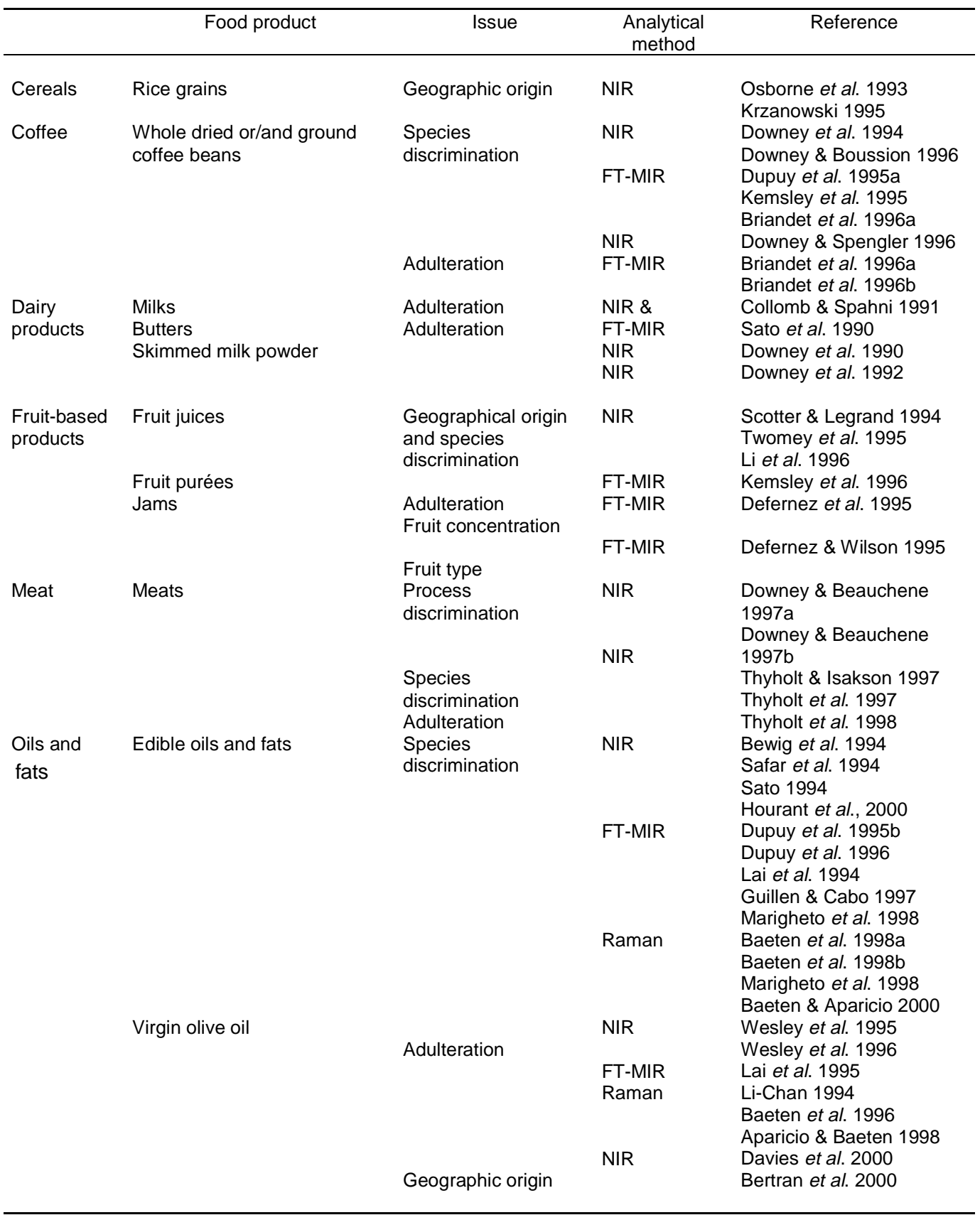

studies try to calibrate the spectrometer to detect compounds known as indicators in the detection of food product adulteration. These strategies are complementary and need to be investigated when a study is done on the potential of a spectroscopic technique (Aparicio and Baeten 1998). One example is the successful attempt to calibrate the Raman or MIR spectrometers for the measurement of trilinolein (LLL) in virgin olive (Baeten et al. 1996; Aparicio and Baeten 1998). In this study, virgin olive oil spiked with LLL was used to calibrate the spectrometer. Trilinolein (determined by liquid or gas chromatography) is a chemical indicator which allows the detection of adulteration of virgin olive oil with seed oils to be traced (Aparicio 2000). Similarly, in a recent study it was demonstrated that an NIR spectrometer could be calibrated to quantify different chemical parameters (e.g., protein, water and fat content) and then to use the results to check the sample's compliance with the specifications for Belgian hams, "Jambon d'Ardenne" 
(Dardenne et al., unpublished results). The chemometric technique used in the papers listed in Table II involves two procedures: (i) working with a determined number of variables (i.e., absorbances or scattering intensity) or (ii) working with all the variables using condensed chemometric techniques such those based on principal component analysis. In the past few years, an additional chemometric procedure for authentication with spectroscopic data has been proposed by various authors; it is based on hierarchical classification (also called sequential stepwise identification) to address authentication problems (Aparicio and Baeten 1998; Baeten and Aparicio 2000). With this procedure, a series of classification rules are constructed (according to the same or different multivariate techniques) and organised to authenticate a food product. The hierarchical procedure is very attractive as it allows for instance the combination of different discriminant equations, with data coming from different spectral regions or different spectroscopic techniques.

Although the papers listed in Table II demonstrate the potential of NIR, MIR and Raman spectroscopy in the authentication of food products, none addresses the feasibility of using these methods in the daily control of authenticity. To achieve this goal, it will be necessary to develop the tools for the construction, management and exploitation of the reference databases. Indeed, all the developed and proposed methods based on spectroscopy require a relevant references database. The appropriate chemometric tools for exploiting this database need to be developed and standardised.

\section{REFERENCES}

Acha, V., Naveau, H., Meurens, M. (1998). Extractive sampling methods to improve the sensitivity of FTIR spectroscopy in analysis of aqueous liquids. Analusus, 26, 157-163.

Adam, M., Chew, M., Wasseram, S., McCollum, A., McDonald, R.E., Mossoba, M.M. (1998). Determination of trans Fatty Acids in Hydrogenated Vegetable Oils by Attenuated Total Reflection Infrared Spectroscopy : Two Limited Collaborative Studies. J. Amer. Oil Chem. Soc., 75, 3, 353-358.

Adam, M., Mossoba, M.M., Dawson, T., Chew, M. Wasserman, S. (1999). Comparison of Attenuated Total Reflection Infrared Spectroscopy to Capillary Gas Chromatography for trans Fatty Acid Determination. J. Amer. Oil Chem. Soc., 76, 3, 375-378.

Adam, M., Mossoba, M.M., Lee, T. (2000). Rapid Determination of Total trans Fat Content by Attenuated Total Reflection Infrared Spectroscopy : An International Collaborative Study. J. Amer. Oil Chem. Soc, 77, 5, 457-462.

Afran, A. (1993). FTIR absorbance linearity of square column ATR for the analysis of aqueous solutions, International Laboratory, 1, 14-18.

Afran, A., Newbery, J.E. (1991). Analysis of the degree of unsaturation in edible oils by Fourier transforminfrared/attenuated total reflectance spectroscopy. Spect. Internat., 3, 39-42.
Alonso, L., Fraga, M.J., Juarez, M. (2000). Determination of trans Fatty Acid Profiles in Margarines Marketed in Spain. J. Amer. Oil Chem. Soc., 77, 2, 131-136.

Aparicio, A. (2000). Characterization: Mathematical procedures for chemical analysis. In: Handbook of Olive Oil: Analysis and Properties (Eds: J.L. Harwood and R. Aparicio); Chapman \& Hall, London, U.K. Chapter 10, pp. 285-353.

Aparicio, R., Baeten, V. (1998). Authentication of virgin olive oil by FT-MIR and FT-Raman spectroscopy. Final report. European Communities Commission (FAIR, CT-96-5053).

Aparicio, R., Alonso, V., Morales, M.T. (1996a). Developments in olive oil authentication. Proc. Food Authenticity'96. Norwich, U.K.

Baeten, V., Aparicio R. (2000). Edible oils and fats authentication by Fourier transform Raman spectrometry. Biotechnol. Agrom. Soc. Environ. 4, 196-203.

Baeten, V., Aparicio, R., Marigheto, N.A., Wilson, R.H. (2000). Olive oil analysis by infrared and Raman spectroscopy: methodologies and applications. In: Handbook of Olive Oil: Analysis and Properties (Eds: J.L. Harwood and R. Aparicio); Chapman \& Hall, London, U.K. Chapter 8, pp. 207-245.

Baeten, V., Hourant, P., Morales, M.T., Aparicio, R. (1998a). Oil and fat classification by FT-Raman spectroscopy. $J$. Agric. Food Chem., 46, 2638-2646.

Baeten, V., Morales, M.T., Aparicio, R. (1998b). Oil and fat analysis by FT-Raman spectroscopy. In: Advances in Lipids Research (Eds. Sanchez, J.; Cerda-Olmedo, E.; Martinez-Force, E.), Univesity of Seville, Spain, pp. 18-21.

Baeten, V., Meurens, M., Morales, M.T., Aparicio, R. (1996). Detection of virgin olive oil adulteration by Fourier transform Raman spectroscopy. J. Agric. Food Chem., 44, 2225-2230.

Bailey, G.F., Kint, S., Scherer, J.R. (1967). A new Raman microsampling technique. Anal. Chem., 39, 1040-1044.

Bailey, G.F., Horvat, R.J. (1972). Raman spectroscopic analysis of the cis/trans isomer composition of edible vegetable oils. J. Am. Oil Chem. Soc., 49, 494-498.

Baranska, H. (1987). An introduction to Raman scattering. In: Laser Raman Spectrometry: Analytical Applications (Eds: H. Baranska, A. Labudzinska and J. Terpinski); Ellis Horwood, Chichester, U.K. pp 9-31.

Baranska, H., Labudzinska, A., Terpinski, J. (1987). Laser Raman Spectrometry: Analytical Applications; Ellis Horwood: Chichester, UK.

Barclay, V.J., Bonner, R.F. (1997). Application of Wavelet Transforms to Experimental Spectra : Smoothing, Denoising, and Data Set Compression. Analytical Chemistry, 69, 1, 78-90.

Belton, P.S., Wilson, R.H., Sadeghi-Jorabchi, H., Peers, K.E. (1988), A rapid method for the determination of isolated trans double bonds in oils and fats using Fourier transform infrared spectroscopy combined with attenuated total reflectance, Lebensm. Wiss. $u$. Technol., 21, 153-157.

Bertan, E., Blanco, M., Coello, J., Iturriaga, H., Maspoch, S., Montoliu, I. (2000). Near infrared spectrometry and pattern recognition as screening methods for the authentication of virgin olive oils of very close geographical origins. J. Near Infrared Spectroscop., 8, 45-52.

Bertrand, D. (1998). Principe de fonctionnement de spectromètres proche infrarouge de conception récente. Analusis Magazine, 26, 4, M29-M33.

Bertrand, B. (2000). Les méthodes d'analyse rapide dans les industries agroalimentaires. In La spectroscopie 
infrarouge et ses applications analytiques (Eds. Bertrand and Dufour), Chapter 1, pp. 3-30.

Bertrand, B., Dufour, E. (2000). La spectroscopie infrarouge et ses applications analytiques. TEC \& DOC, Paris, France.

Bertrand, B., Courcoux, P., Qannari E.M. (2000). Méthodes exploratoire in La spectroscopie infrarouge et ses applications analytiques (Eds. Bertrand and Dufour), Chapter 11, pp.267-294.

Bertrand, D., Robert, P., Rouxel, C. (1989), Hierarchical clustering of NIR spectra. Proc. of the $2^{\text {nd }}$ International NIRS conference, Tsukuba, Japan. 241-248.

Bewig, K.M., Clarke, A.D., Roberts, C., Unklesbay, N. (1994). Discriminant analysis of vegetable oils by near-infrared reflectance spectroscopy. J. Am. Oil Chem. Soc., 71, 195-200.

Bouveresse, E., Massart, D.L., Dardenne, P. (1994). Calibration transfer across near-infrared spectrometic instruments using Shenk's algorithm : effects of different standardisation samples. Analytica Chimica Acta, 297, 405-416.

Briandet, R., Kemsley, E.K., Wilson, R.H. (1996a). Discrimination of Arabica and Robusta in instant coffees by Fourier transform infrared, chemometrics. $J$. Agric. Food Chem, 44, 170-174.

Briandet, R., Kemsley, E.K., Wilson, R.H. (1996b). Approaches to adulteration detection in instant coffees infrared spectrometry. J.Sci. Food Agric., 71, 359-366.

Brown, S.D.(1995). Chemical systems under indirect observation: Latent properties and Chemometrics. Applied Spectroscopy, 49, 14A-31A.

Chaminade, P., Baillet, A., Ferrier, D. (1998). Data treatment in near infrared spectroscopy. Analusis Magazine, 26, 4, M33-M38

Chase, B. (1987). Fourier transform Raman spectroscopy. Anal. Chem., 59, 881A-889A.

Chevalier, O., Dardenne, P., Deroanne, Cl., Biston, R. (1990). Determination of moisture, protein, fat and collagen in fresh meat by near infrared spectroscopy. In Proceeding of the $3^{\text {rd }}$ ICNIRS, 25-29 june 1990, Brussels, Belgium.

Ciurczak, E.W. ( 1991). What's new in Spectroscopy Instrumentation? Spectroscopy Int., 3 (3), 18-30.

Coates, J., Sanders, A. (2000). A universal sample handling system for FT-IR spectroscopy. Spectroscopy Europe, 12-22.

Collomb, M., Spahni, M. (1991). Adulteration of milk products. Review of the analytical Criteria for the detection of vegetable and animal fats in milk fat.. Trav. Chim. Aliment. Hyg, 82, 615-662.

Cox, R., Lebrasseur, J., Michiels, E., Buijs, H., Li, H., van de Voort, F.R., Ismail, A.A., Sedman, J. (2000). Determination of lodine Value with a Fourier Transform-Near Infrared Based Global Calibration Using Disposable Vials: An International Collaborative Study. J. Amer. Oil Chem. Soc., 77, 12, 1229-1234.

Cowe, I.A., McNicol, J.W. (1985). The use of principal components in the analysis of near-infrared spectra. Applied Spectroscopy, 39, 257-266.

Cowe, I.A., McNicol, J.W., Cuthbertson, D.C. (1985a), A designed experiment for the examination of techniques used in the analysis of near-infrared spectra. Part 1. Analysis of spectral structure, Analyst, 110, 1227-1232.

Cowe, I.A., McNicol, J.W., Cuthbertson, D.C. (1985b). A comparison of the shapes of the principal component and partial least squares factors obtained from near infrared spectra. Shapes of principal component and PLS factors. Analyst, 110, 191-199.
Dardenne, P., Welle, R. (1998). New approach for calibration transfer from a local database to a global database. Near Infrared Spectrosc., 6, 55-60.

Dardenne, P., Sinnaeve, G., Baeten, V. (2000). Multivariate calibration and chemometrics for near infrared spectroscopy : which method? J. Near Infrared Spectrosc., 8, 229-237.

Davies, A.N., Mclntyre, P., Morgan, E. (2000). Study of the Use of Molecular Spectroscopy for the Authentication of Extra Virgin Olive Oils. Part I: Fourier Transform Raman Spectroscopy. Applied Spectroscopy, 54, 12, 1864-1875.

Davies, A.M.C. (1994). The year of the Neural Network. Spectroscopy Europe, 27-28.

Davies, T. (1998). The history of near infrared spectroscopic analysis : Past, present and future "From sleeping technique to the morning star of spectroscopy". Analusis magazine, 26, 4, M17-M19.

Defernez, M., Kemsley, E.K., Wilson, R.H. (1995). Use of infrared spectroscopy and chemometrics for the authentication of fruit purees. J. Agric Food Chem., 43, 109-113.

Defernez, M., Wilson, R.H. (1995). J. Sci Food Agric., 67, 461-467.

De Greyt, W., Kint, A., Kellens, M., Huyghebaert, A. (1998). Determination of Low trans Levels in Refined Oils by Fourier Transform Infrared Spectroscopy. J. Amer. Oil Chem. Soc .,75, 2, 115-118.

Dennis, M.J., Ashurst, P.R. (1996). An introduction to food authentication. In Food Authentication (Eds: P.R. Ashurst and M.J. Dennis); Chapman \& Hall, Cambridge, U.K. Chapter 1, pp 1-14.

De Pedro, E., Garrido, A., Bares, I., Casillas, M., Murray, I. (1992). Application of near infrared spectroscopy for qualitycontrol of Iberian pork industry. In Proceeding of the $5^{\text {th }}$ ICNIRS. June 1992, Haugesund, Norway.

Diem, M. (1993). Introduction to modern vibrational spectroscopy; Wiley: New York, Ny, USA.

Dou, X., Jung, Y.M., Cao, Z.Q., Ozaki, Y. (1999). Surface-Enhanced Raman Scattering of Biological Molecules on Metal Colloid II : Effects of Aggregation of Gold Colloid and Comparison of Effects of $\mathrm{pH}$ of Glycine Solutions between Gold and Silver Colloids. Applied Spectroscopy, 53, 11, 1440-1447.

Downey, G., Beauchene, D. (1997). Authentication of fresh versus frozen then thawed beef by near-infrared reflectance spectroscopy of dried drip juice. LebensmittelWissenschaff und Technology, 30, 721-726.

Downey, G., Beauchene, D. (1997). Discrimination between fresh and frozen-then-thawed beef (M. longissimus dorsi) by combined visible-near infrared reflectance spectrsocopy: a feasability study. Meta Science, 45, 353-363.

Downey, G., Boussion, J. (1996). Authentication of coffee beans variety by near-infrared reflectance spectroscopy of dried extract. J. Sci. Food Agric., 71, 41-49.

Downey, G. Boussion, J., Beauchêne, D. (1994) Authentication of whole and ground coffee beans by near infrared reflectance spectroscopy. JNIRS, 2, 85-92.

Downey, G., Robert, P., Bertrand, D. (1992). Qualitative analysis in the NIR Region: a whole spectrum approach. Analytical Proceedings, 29, XXX

Downey, G., Robert, P., Bertrand, D., Kelly, P.M. (1990). Classification of commercial skim milk powder according to heat treatment using factorial discriminant analysis of near-infrared reflectance spectra. Applied Spectroscopy, 44, 150-156. 
Downey, G., Spengler, B. (1996). Compositional analysis of coffee blends by near infrared spectroscopy. J. Agric. Food Res., 35, 179-188.

Dubois, J., van de Voort, F.R., Sedman, J., Ismail, A.A., Ramaswamy, H.R. (1996). Quantitative Fourier transform infrared analysis for anisidine value and aldehydes in thermally stressed oils. J. Am. Oil Chem. Soc, 73, 787-794.

Duponchel, L., Ruckebusch C., Huvenne J.P., Legrand, P. (1999). Standardisation of near infrared spectrometers using artificial neurel networks. Near infrared Spectrosc., 7, 155-166.

Dupuy, N., Huvenne, J.P., Legrand, P., Le Bourlant, R. (1995b). Application of optical fiber / FTIR coupling classification of vegetable oils by analysis of principal components of infrared analysis. Spectra. Anal., 24, 36-41.

Dupuy, N., Huvenne, J.P., Duponchel, L., Legrand, P. (1995a). Classification of green coffees by FT-IR analysis of dry extract. Applied Spectroscopy, 49, 580-585.

Ellis, G., Hendra, P.J., Hodges, C.M., Jawhari, T., Jones, C., Le Barazer, P., Passingham, C., Royaud, I.A.M., Sanchez-Blasquez, A., Warnes, G.M. (1989). Routine Analytical Fourier Transform Raman Spectroscopy. Analyst, 114, 1061-1066.

Favier, J.P., Bicanic, D., van de Bovenkamp, P., Chirtoc, M., Helander, P. (1996). Detection of Total Trans Fatty Acids Content in Margarine: An Intercomparison Study of GLC, GLC + TLC, FT-IR, and Optothermal Window (Open Photoacoustic Cell). Anal. Chem. 68, 729-733.

Fearn, T. (1999). Chemometric Space: A look at some standard pre-treatments for spectra. NIR news, 10 (3), 10-11.

Fearn, T. (2000). Chemometric Space : Savitsky-Golay filters. NIR news, 11(6) 14-15.

Fearn, T. (2001). Chemometrics for near infrared spectroscopy: past present and future. Spectroscopy Europe, 10-14.

Fumière, O., Sinnaeve, G., Dardenne, P. (2000). Rapid authentication of certified chicken meat : distinguishing slow and fast growing chicken strains using near infrared reflectance spectroscopy. BASE, 4, 214-220.

Garcia-Olmo, J., De Pedro, E., Garrido, A. (1998). Methodological aspects of near infrared analysis of Iberian pig using interactance-reflectance fiber optic mode. J. Near Infrared Spectroscopy, 6, A307-A312.

Gerrard, D.L. (1991). Organic and petrochemical applications of Raman spectroscopy. In Analytical Raman spectroscopy (Eds: J.G. Grasselli and B.J. Bulkin); Miller and Stace, New York, USA. Chapter 9, pp 275-325.

Grasseli, J.G., Bulkin, B.J. (1991). Analytical Raman Spectroscopy; Wiley: New York, USA.

Griffiths, P.R. (1972). Fourier Transform Spectroscopy. Laboratory Methods in Infra-Red, 84-96.

Guillén, M.D., Cabo, N. (1997). Characterization of Edible Oils and Lard by Fourier Transform Infrared Spectroscopy. Relationships Between Composition and Frequency of Concrete Bands in the Fingerprint Region. J. Amer. Oil Chem. Soc., 74, 1281-1286.

Harrick, N. (1967) Internal Reflection Spectroscopy, John Wiley and Sons, New York.

Hendra, P.J. (1993). Fourier transform Raman spectroscopy in pharmaceutical analysis and research. Int. Laboratory, 13A-13I.

Hourant, P., Baeten, V., Morales, M.T., Meurens, M., Aparicio, R. (2000). Oil and Fat Classification by selected bands of near-infrared spectroscopy. Applied Spectroscopy, 54, 1168-1174.

Howard, M. (1989). Chemometrics in near-infrared spectroscopy. Anal. Chim. Acta, 223, 75-93.

Ismail, A.A., van de Voort, F.R., Emo, G., Sedman, J. (1993). Rapid quantitative determination of free fatty acids in fats and oils by Fourier transform infrared spectroscopy. J. Am. Oil Chem. Soc., 70, 335-341.

Jouan-Rimbaud, D., Massart, D.L., Leardi,R., De Noord, O.E. (1995). Genetic Algorithms as a Tool for Wavelength Selection in Multivariate Calibration. Anal. Chem., 67, 4295-4301.

Keller, S., Löchte, T., Dippel, B., Schrader, B. (1993). Quality control of food with near-infrared excited Raman spectroscopy. Fresenius J.Anal.Chem., 346, 863-867.

Kemsley, E.K. (1996). Lies, damned lies and chemometrics. Proceeding of the European Symposium of Food Authenticity. Nantes.

Kemsley, E.K., Holland, J.K., Wilson, R.H. (1996). Detection of adulteration of raspberry purées using infrared spectroscopy and chemometrics. J. Agric. Food Chem., 44, 3864-3870.

Kemsley, E.K., Ruault, S., Wilson, R.H. (1995). Discrimination between Coffea arabica and Coffea canephora variant robusta beans using infrared spectroscopy. Food Chemistry, 54, 321-326.

Krzanowski, W.J. (1995) The authentication of Basmati rice using near infrared spectroscopy, some further analysis JNIRS, $3,111-117$.

Lachenal, G. (1998). Analyse par spectroscopie proche infrarouge (PIR) et applications aux polymères. Analusis Magazine, 26, M20-M29.

Lai, Y.W., Kemsley, E.K., Wilson, R.H. (1994). Potential of Fourier transform infrared spectroscopy for the authentication of vegetable oils. J. Agric. Food Chem., 42, 1154-1159.

Lai, Y.W., Kemsley, E.K., Wilson, R.H. (1995). Quantitative analysis of potential adulterants of extra virgin olive oil using infrared spectroscopy. Food Chemistry, 53, 95-98.

Lanser, A.C., List, G.R., Holloway, R.K., Mounts, T.L. (1991), FTIR estimation of free fatty acid content in crude oils extracted from damaged soybeans, J. Amer. Oil Chem. Soc., 68, 448-449.

Laporte, M.F., Paquin, P. (1999). Near-Infrared Analysis of Fat, Protein, and Casein in cow's Milk. J. Agric. Food. Chem, 47, 2600-2605.

Le Cacheux, P., Ménard, G., Nguyen Quang, H., Nguyen Quy Dao, Roach, A.G., Dron, D. (1996). Quantitative determination of free and esterified cholesterol concentrations in cholesterol-fed rabbit aorta using near-infrared- Fourier transform-Raman spectroscopy. Spectrochim. Acta Part A, 52, 1619-1627.

Lees, M. (1996). Food Authenticity: Issues and methodologies. Introduction. Proc.Orientation Meeting of FAIM Concerted Action AIR3-CT94-2452. Nantes France, May 11-12 th.

Levin, I.W., Lewis, E.N. (1990). Fourier transform Raman spectroscopy of biological materials. Anal. Chem., 62, 1101A-1111A.

Lewis, E.N., Kalasinsky, V.F., Levin, I.W. (1988). Near-infrared Fourier transform Raman spectroscopy using fiber-optic assemblies. Anal. Chem., 60, 2658-2661.

Li, H., van de Voort, F.R., Ismail, A.A., Sedman, J., Cox, R. (2000). Trans Determination of Edible Oils by Fourier Transform Near-Infrared Spectroscopy. J. Amer. Oil Chem. Soc., 77, 10, 1061-1067.

Li, H., van de Voort, F.R., Ismail, A.A., Cox, R. (2000). Determination of Peroxide Value by Fourier Transform 
Near-Infrared Spectroscopy. J. Amer. Oil Chem. Soc., 77, 2, 137-142.

Li, W., Goovaerts, P., Meurens, M. (1996). Quantitative analysis of individual sugars and acids in orange juices by near-infrared spectroscopy of dry extract. J. Agric. Food Chem., 44, 2252-2259.

Li-Chan, E. (1994). Developments in the detection of adulteration of olive oil. Trends Food Sci. Tech., 5, 3-11.

Li-Chan, E. (1996). The applications of Raman spectroscopy in food science. Trends Food Sci. Tech., 7, 361-370.

Ma, K., van de Voort, F.R., Ismail, A.A., Zhuo, H., Cheng, B. (2000). Monitoring Peroxide Value in Fatliquor Manufacture by Fourier Transform Infrared Spectroscopy. J. Amer. Oil Chem. Soc., 77, 6, 681-685.

Ma, K., van de Voort, F.R., Sedman, J., Ismail, A.A. (1997). Stoichiometric Determination of Hydroperoxides in Fats and Oils by Fourier Transform Infrared Spectroscopy. J. Amer. Oil Chem. Soc., 74, 8, 897-906.

Marigheto, N.A., Kemcley, E.K., Defernez, M., Wilson, R.H. (1998). A comparison of Mid-Infrared and Raman spectroscopies for the authentication of edible oils. $J$. Amer. Oil Chem. Soc., 75, 987-992.

Martin, P. (1996). Internal document of Food Authenticity Issues and Methodologies. European Communities Concerted Action AIR3-CT94-2452: Nantes, France, May $11-12^{\text {th }}$.

Martens, H., Næs, T. (1989). Multivariate Calibration;Wiley: Chichester, U.K.

McCreery, R.L. (2000). Raman Spectroscopy for Chemical Analysis; Wiley: NY, USA.

Merlin, J.C., Statoua, A, Cornard, J.P., Saidi-Idrissi, M., Brouillard, R. (1994). Resonance Raman Spectroscopic Studies of Anthocyanins and Anthocyanidins in Aqueous Solutions. Phytochemistry, 35, 227-232.

Mossoba, M.M., Yurawecz, M.P., McDonald, R.E. (1996), Rapid determination of the total trans content of neat hydrogenated oils by attenuated total reflection spectroscopy, J. Amer. Oil Chem. Soc., 73, 1003-1009.

Murray, I. (1999). NIR spectroscopy of food : single things, subtle things and spectra. NIR news, 10, 10-12.

Olinga, A., Siesler, H.W. (2000). Quality control and process monitoring by vibrational spectroscopy. NIR news, 11, 9-13.

Osborne, B.G., Fearn, T. (1986). Near-Infrared Spectroscopy in Food Analysis; Longman, Wiley: NY, USA.

Osborne, B.B., Mertens, B., Thompson, M., Fearn, T. (1993) The authentication of Basmati rice using near infrared spectroscopy. JNIRS, 1, 77-84.

Ozaki, Y., Cho, R., Ikegaya, K., Muraishi, S., Kawauchi, K. (1992). Potential of near-infrared Fourier transform Raman spectroscopy in food analysis. Applied Spectroscopy, 46, 1503-1507.

Panford, J.A., de Man, J.M. (1990). Determination of oil content of seeds by NIR: influence of fatty acid composition on wavelength selection. J. Amer. Oil Chem. Soc., 67, 473-482.

Pelletier, M., Davis, K. (1996). Raman spectroscopy: the next generation. Int. Laboratory, 11D-11G.

Piraux, F., Dardenne, P. (1999). Application of the NIR-microscopy to the analysis of feedstuffs. BASE, 4 , 226-232.

Roger, J.M., Bellon-Maurel, V. (2000). Using Genetic Algorithms to select Wavelengths in Near-Infrared Spectra : Application to Sugar Content Prediction in Cherries. Applied Spectroscopy, 54, 1313-1320.

Sadeghi-Jorabchi, H., Hendra, P.J., Wilson, R.H., Belton, P.S. (1990). Determination of the total unsaturation in oils and margarines by Fourier transform Raman spectroscopy. J. Amer. Oil Chem. Soc., 67, 483-486.

Sadeghi-Jorabchi, H., Wilson, R.H., Belton, P.S., Edwards-Webb, J.D., Coxon, D.T. (1991). Quantitative analysis of oils and fats by Fourier transform Raman spectroscopy. Spectrochim. Acta, 47A, 1449-1458.

Safar, M., Bertrand, D., Robert, P., Devaux, M.F., Genot, C. (1994).Characterization of edible oils, butters and margarines by Fourier transform infrared spectroscopy with attenuated total reflectance. J. Amer. Oil Chem. Soc. 71, 371-377.

Saint-Pierre Chazalet, M., Masson, M., Bousquet, C., Bolbach, G., Ridente, Y., Bolard, J. (1994). Surface-enhanced Raman scattering studies of lipid planar bilayers in water. Thin Solid Films, 244, 852-856.

Sato, T. (1994). Application of principal-component analysis on near-infrared spectroscopic data of vegetable oils for their classification. J. Amer. Oil Chem. Soc., 71, 293-298.

Savitzki, A., Golay, M.J.E. (1964). Smoothing and differentiation of data by simplified least squares procedures. Anal. Chem., 36, 1627-1630.

Schrader, B. (1996). Raman spectroscopy in the near-infrared - a most capable method of vibrational spectroscopy. Fresenius J. Anal. Chem., 355, 233-239.

Scotter, C.N.G. (1997). Non-destructive spectroscopic techniques for the measurement of food quality. Trends Food Sci. Tech., 8, 285-292.

Scotter, C.N.G., Legrand, A. (1994). NIR qualitative analysis - a new philosophy with special reference to rapid NIR screening of fruit juice authenticity. Food Sci. Technol. Today, 8(3), 167-171.

Sedman, J., van de Voort, F.R., Ismail, A.A. (1997). Upgrading the AOCS Infrared trans Method for Analysis of Neat Fats and Oils by Fourier Transform Infrared Spectroscopy. J. Amer. Oil Chem. Soc., 74, 8, 907-913.

Sedman, J., van de Voort, F.R., Ismail, A.A. (2000). Simultaneous Determination of lodine Value and trans Content of Fats and Oils by Single-Bounce Horizontal Attenuated Total Reflectance Fourier Transform Infrared Spectroscopy. J. Amer. Oil Chem. Soc., 77, 4, 399-403.

Sinnaeve, G., Baeten, V., Tissot, S., Dardenne P., Frankinet, M. (2000). Application d'un spectrometer NIR à barrettes de diode pour l'analyse de céréales au niveau de la moissonneuse batteuse. Poster presented at the "Après-midi d'étude sur l'Agriculture de précision", 20/12/2000, Gembloux, Belgium.

Sinnaeve, G., Dardenne, P., Biston, R. (1990). Prediction of fat, moisture and solids not fat content of butter by near infrared reflectance spectroscopy. In Proceeding of the $3^{\text {rd }}$ ICNIRS, 25-29 june 1990, Brussels, Belgium.

Simpkins, W., Harrison, M. (1995). The state of the art in authenticity testing. Trends Food Sci. Technol., 6, 321-328.

Socrates, G. (1994). Infrared Characteristic Group Frequencies: Tables and Charts; John Wiley \& Sons: New York, NY, USA.

Terpinski, J. (1987). Identification of organic compounds. In Laser Raman Spectrometry: Analytical Applications (Eds: H. Baranska, A. Labudzinska, J. Terpinski); Ellis Horwood, Chichester, U.K. Chapter 4, pp 79-141.

Thyholt, K., Isakson, T. (1997). Differentiation of frozen and unfrozen beef using near-infrared spectroscopy. J. Sci. Food Agric., 73, 525-532.

Thyholt, K., Indahl, U.G., Hildrum, K.I., Ellejaer M.R. (1997). Meat speciation by near infrared reflectance 
spectroscopy on dry extract. J. Near Infrared Spectrosc., 5, 195-208.

Thyholt, K., Isakson, T., Hildrum, K.I., Ellejaer M.R., Eide, O.C. (1998). Detecting non-bovine meat in beef patties by dry extract spectroscopy by infrared reflection - a preliminary study. J. Near Infrared Spectrosc., 6, A361-A362.

Twoney, M., Downey, G., McNulty, P.B. (1995). The potential of NIR spectroscopy for the detection of adulteration of orange juice. J. Sci. Food Agric., 67, 77-84.

Ulberth, F., Haider, H.-J. (1992). Determination of low level trans unsaturation in fats by Fourier transform infrared spectroscopy, J. Food Sci., 57, 1444-1447.

van de Voort, F.R., Ismail, A.A. (1991). Proximate analysis of foods by mid-FTIR spectroscopy. Trends Food Sci. Tech., 13-17.

van de voort, F.R., Sedman, J., Emo, G., Ismail, A.A. (1992a). Assessment of Fourier Transform Infrared Analysis of Milk. J. AOAC Int., 75, 780-785.

van de Voort, F.R., Sedman, J., Emo, G., Ismail, A.A. (1992b). Rapid and direct iodine value and saponification number determination of fats and oils by attenuated total reflectance/Fourier transform infrared spectroscopy. J. Amer. Oil Chem. Soc., 69, 1118-1123.

van de Voort, F.R., Sedman, J., Emo, G., Ismail, A.A. (1993). A rapid FTIR quality-control method for determining fat and moisture in high-fat products. Anal. Chemistry, 48, 213-221.

van de voort, F.R. (1994). FTIR spectroscopy in edible oil analysis. Inform, 5, 1038-1042.

van de Voort, F.R., Ismail, A.A., Sedman, J. (1995). A rapid automated method for the determination of cis and trans content of fats and oils by Fourier transform infrared spectroscopy. J. Amer. Oil Chem. Soc., 72, 873-880. van de Voort, F.R., Memon, K.P., Sedman, J., Ismail, A.A. (1996), Determination of solid fat index by Fourier transform infrared spectroscopy, J. Amer. Oil Chem. Soc., 73, 411-416.

Vickers, T.J., Mann, C.K. (1991). Quantitative analysis by Raman spectroscopy. In: Analytical Raman spectroscopy (Eds: J.G. Grasselli and B.J. Bulkin); Miller and Stace, NY, USA. Chapter 5, pp 107-135.

Weldon, M.K., Morris, M.D. (2000). Surface-Enhanced Raman Spectroscopic Investigation of Bacterial Lipolysis in a Skin Pore Phantom. Applied Spectroscopy, 54, 20-23.

Wesley, I.J., Barnes, R.J., McGill, A.E.J. (1995). Measurement of adulteration of olive oils by near-infrared spectroscopy. J. Amer. Oil Chem. Soc., 72, 289-292.

Wesley, I.J., Pacheco, F., McGill, A.E.J. (1996). Identification of adulterants in olive oils. J. Am. Oil Chem. Soc., 73, 515-518.

Wetzel, D.L., Reffner, J.A. (2000). Infrared spectroscopy goes microscopic. Chemistry \& Industry, 308-313.

Williams, K.P.J., Batchelder, D.N. (1994). Raman microscopy-spectroscopy and direct two dimensional imaging. Spectroscopy Europe, 6, 19-26.

Wilson, R.H. (1990). Fourier transform mid-infrared spectroscopy for food analysis. Trends Anal. Chem., 9, 127-131.

Wilson, R.H., Tapp, H.S. (1999). Mid-infrared spectroscopy for food analysis : recent new applications and relevant developments in sample presentation methods. Trends Anal. Chem., 18, 85-93.

Yang, J., Huang, Y.S. (2000). IR Chemical Sensor for Detection of Aromatic Compounds in Aqueous Solutions Using Alkylated Polystyrene-Coated ATR Waveguides. Applied Spectroscopy, 54, 202-208. 